\title{
Reverse thinking: taking a healthy diet perspective towards food systems transformations
}

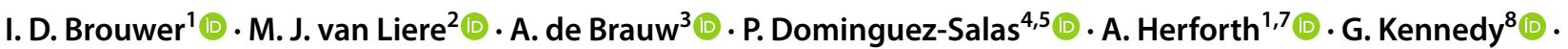

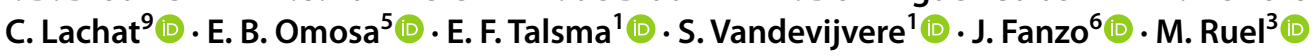

Received: 16 March 2021 / Accepted: 16 July 2021 / Published online: 16 October 2021

(c) The Author(s) 2021

\begin{abstract}
Food systems that deliver healthy diets without exceeding the planet's resources are essential to achieve the worlds' ambitious development goals. Healthy diets need to be safe, accessible, and affordable for all, including for disadvantaged and nutritionally vulnerable groups such as of smallholder producers, traders, and consumers in low- and middle-income countries. Globally, food systems are experiencing rapid and drastic changes and are failing to fulfil these multiple duties simultaneously. The international community therefore calls for rigorous food systems transformations and policy solutions to support the achievement of healthy diets for all. Most strategies, however, are essentially supply- and market-oriented. Incorporation of a healthy diet perspective in food system transformation is essential to enable food systems to deliver not only on supplying nutritious foods but also on ensuring that consumers have access can afford and desire healthy, sustainable, and culturally acceptable diets. This paper argues that this should be guided by information on diets, dietary trends, consumer motives, and food environment characteristics. Transformational approaches and policies should also take into account the stage of food system development requiring different strategies to ensure healthier diets for consumers. We review current knowledge on drivers of consumer choices at the individual and food environment level with special emphasis on low- and middle income countries, discuss the converging and conflicting objectives that exist among multiple food-system actors, and argue that failure to strengthen synergies and resolve trade-offs may lead to missed opportunities and benefits, or negative unintended consequences in food system outcomes. The paper proposes a menu of promising consumer- and food-environment- oriented policy options to include in the food systems transformation agenda in order to shift LMIC consumer demand towards healthier diets in low- and middle income countries.
\end{abstract}

Keywords Food systems transformation $\cdot$ Healthy diets $\cdot$ Sustainability $\cdot$ Cost of diet $\cdot$ Animal-sourced foods $\cdot$ Ultraprocessed foods $\cdot$ Food environment $\cdot$ Consumer choices $\cdot$ Policies

\section{Introduction}

Diets play a central role in food systems (GLOPAN, 2020), and are either seen as a 'victim' or outcome of food systems (where diets change due to urbanization, changing food environments and climate change constraints), or as an 'instigator'

This article belongs to the Topical Collection: Food System Transformations for Healthier Diets, Inclusive Livelihoods and Sustainable Environment

Guest Editors: Romina E Cavatassi, Leslie Lipper, Ruerd Ruben, Eric Smaling, Paul Winters

\section{D. Brouwer}

inge.brouwer@wur.nl

Extended author information available on the last page of the article or driver (where food systems transitions are seen as a consequence of changing consumer demand due to shifts in dietary patterns and population growth). Irrespective of perspective, there is a growing recognition of the need to improve diet quality and reduce inequalities in access to nutritious, affordable and sustainably-produced foods in all countries. Poor diets are a major driver of malnutrition, mortality and morbidity worldwide, exceeding the burdens attributable to many other global health challenges (GBD, 2017; Diet Collaborators, 2019). While some progress has been made in reducing the prevalence of undernutrition (stunting and wasting), micronutrient deficiencies persist and the prevalence of overweight, obesity and diet-related non-communicable diseases (NCDs) is rising across the globe, the fastest in low-income countries (LICs) (Development Initiatives, 2020; Popkin et al., 2020). 
Most countries are burdened by multiple forms of malnutrition, especially low- and middle-income countries (LMICs) (Popkin et al., 2020). Inequalities in malnutrition are largely driven by socio-economic disparities (determined by location, wealth, and education), and compounded by conflict and other forms of fragility (Development Initiatives, 2020). Improving the quality of diets is one of the key strategies to prevent or reverse all forms of malnutrition and related NCDs.

A global nutrition transition-described as a shift from diets with a high proportion of a limited set of staples toward more diversified diets that are higher in energy and macronutrients, as well as in specific food groups, such as meat, sugar, processed foods and foods eaten outside the home-was documented for the first time more than 25 years ago (Popkin, 1993). Current dietary changes are mainly driven by urbanization, increased disposable incomes, societal changes such as greater participation by women in labor markets, and developments in technology, marketing strategies and public policy (Popkin et al., 2020; Vermeulen et al., 2020). People are eating more food and more energy, protein and fats than before and although individual diets have diversified, diets have become more homogenous globally, relying on the same small number of traded commodities (Khoury et al., 2014). While consumption of healthy foods (vegetables, fruits, nuts, seed) increased around the world over the period 1990-2010, so did the consumption of foods known to carry health risks (Imamura et al., 2015). Meat consumption increased globally by $20 \mathrm{~kg}$ per capita between 1961 and 2014 (Vermeulen et al., 2020); volume sales of ultra-processed foods (UPFs) and sugar-sweetened beverages (SSB) ${ }^{1}$ increased rapidly worldwide (Vandevijvere et al., 2019a, 2019b); and large heterogeneity has been seen in these dietary changes across regions and countries (Imamura et al., 2015). There is concern, especially for LMICs, that dietary changes are impacting younger population groups and are happening in circumstances where infectious and nutrition-related deficiency diseases continue to persist, creating a dual challenge of undernutrition and problems of overweight and obesity within families, communities and nations (Popkin et al., 2020; Raj, 2020). The impact of these changes on nutrition and health is complex as certain dietary shifts are positive and others are negative in terms of populations meeting national (if available) or global dietary intake recommendations (Mozaffarian, 2016).

Healthy diets are unaffordable for approximately 3 billion people globally (FAO et al., 2020) due to the high cost of nutrient-rich non-staple foods driving consumption patterns among the poor toward cheap, monotonous, starchheavy diets. At the same time, current food systems operate beyond planetary boundaries and contribute significantly to environmental degradation (Rockström et al., 2020), and are

\footnotetext{
${ }^{1}$ UPFs and SBBs are defined as "not modified foods but formulations made mostly or entirely from substances derived from foods and additives with little if any intact food" (Monteiro et al., 2017).
}

fragile to global and local shocks (GLOPAN, 2020). Global consensus is growing that food systems transformation is urgently required to move towards healthy, safe, accessible, affordable and sustainable diets for all, while safeguarding planetary health and reducing poverty and inequality (FAO et al., 2020; GLOPAN, 2020; Young et al., 2019). Despite potential synergies, these disparate goals are often incompatible, and ask for an explicit navigation of trade-offs and active seeking of synergies between the short- and long-term interests of food system actors and outcomes.

We propose the adoption of a healthy diet perspective, whereby consumer needs and preferences are put at the center of food system solutions to enable longer-term consumption shifts through linking healthy food consumption to markets, distribution, production and agriculture (Béné et al., 2019; Brouwer et al., 2020), making sustainable, safe and healthy diets available, accessible, affordable and desirable for all. This paper argues that such a dietary perspective should make use of adequate information on diets, dietary trends, consumer motives and food environment characteristics, to identify possible pathways, research needs and limitations. This could inform commitments for actions and gamechanger solutions following the 2021 UFSS, that lead to transformations towards sustainable and inclusive food system delivering healthy diets for all.

This paper calls for 'reverse thinking' in food system transformations and to start with a healthy diet perspective, identifying consumer choices and food environment characteristics, and addressing these in food system innovations aiming at healthier diets. Section 2 starts with a comprehensive overview of what a healthy (and sustainable) diet is. The evolving diet transitions and dietary gaps at different stages of food system development are described using the data and food system typologies available in the recently launched Food Systems Dashboard (Fanzo et al., 2020). In Sect. 3, we review current knowledge of consumer motives and food environment characteristics, and address challenges with respect to animal sourced foods (ASF), UPFs and affordability of healthy diets, highlighting key tradeoffs. Section 4 describes promising strategies to influence consumer motives directly and indirectly through food environment interventions. Section 5 provides reflections on the importance of incorporating a consumer demand perspective for successful food system transformations and identifying possible pathways of impact, and research needs.

\section{Consumption of a healthy diet: trends and gaps}

\subsection{What is a healthy and sustainably diet?}

A healthy diet ensures adequacy of energy and all essential nutrients, promotes all dimensions of individual health, and prevents malnutrition in all its forms, as well as diet-related NCDs. The exact definition of what a healthy diet should 
consist of will vary depending on individual needs (e.g. age, gender, lifestyle, degree of physical activity), cultural context, locally-available foods and access, and dietary customs (WHO, 2018). But there are generally agreed basic principles of what constitutes a healthy diet and these include diversity and proportionality between food groups; adequate amounts of fruits and vegetables, whole grains, legumes and nuts; and sufficient but not excessive intake of kilocalories, starchy staples and animal-source foods (ASF) (preferring milk, egg, poultry, fish). Definitions of healthy diets go beyond nutrient adequacy and also include avoiding or limiting intake of foods, food groups and nutrients that lead to unhealthy diets when eaten in excess, such as free sugars (including SSBs), types of fat (especially saturated and trans-fat), salt (and if used preferably iodized), red meat, processed meat, and UPF. A healthy diet should also be safe and have only minimal levels, or none if possible, of pathogens, toxins, and other agents that cause foodborne diseases (FAO \& WHO, 2019).

Global optimal levels of intake of different food groups as formulated by WHO (2018) and GBD (2019), based on the best available evidence for protecting health against dietrelated NCDs, do not represent a total diet and need further translation and tailoring to a local contexts. The EAT-Lancet global reference diet is a recent effort to summarize the existing evidence regarding dietary components and patterns that optimize health and minimize the environmental footprint at the same time (Willett et al., 2019), but does not represent a dietary guideline that can be used to inform the general public. Although the global WHO, GBD and EAT-Lancet recommendations largely overlap in food groups, food components and nutrients addressed, there are differences in optimal levels and ranges of intakes recommended; one reason being that contrary to WHO and GBD, the EAT-Lancet recommendations take into account energy and nutrient adequacy (Online Resource 1). National food-based dietary guidelines (FBDG) represent healthy diets in a culturally appropriate dietary pattern for the country in which they are designed, but many countries, especially in sub-Saharan Africa, do not have such guidelines (Herforth et al., 2019) and where they exist, they are not implemented to the full potential due to lack of political support, lack of plan for implementation, non-participation of essential stakeholders, lack of resources and capacity, and conflict with market forces (Wijesinha-bettoni et al., 2021). Global and national dietary guidelines have been underutilized as tools for informing rural investment strategies, both in terms of agricultural development (e.g. research focused on fruits and vegetables, rural-ready cold chains), and safety nets tailored to rural areas to facilitate access to diets that meet dietary guidelines (e.g. distribution of seeds or other supplies for homestead food production).

Sustainable healthy diets are diets with a low environmental impact (evaluated for example by greenhouse gas emissions (GHGE), water and land use data originating from high-income countries (HIC) and urban and industrialized food systems) while being nutritionally adequate (HLPE, 2017). Although healthy diets are not necessarily sustainable (or the other way around), evidence suggests that synergies can be identified (van Dooren et al., 2014; Springmann et al., 2016; Behrens et al., 2017; van de Kamp et al., 2018; Kim et al., 2020a, 2020b). In general, healthy foods and food groups (whole grain, cereals, fruits, vegetables, legumes, nuts and olive oil) have low environmental impacts while processed or red meat have the highest contribution to both disease risk and negative environmental impact (Clark et al., 2019). Where there is an excess in animal sourced food consumption, the sustainability of diets can be strongly improved by re-balancing consumption of meat (particularly ruminant) and dairy (Blackstone et al., 2018; Ritchie et al., 2018; Springmann et al., 2020).

Adoption of FBDGs would lead to a reduced and more positive environmental impact globally (Behrens et al., 2017), but most FBDGs can be strengthened by incorporating environmental and health considerations (Springmann et al., 2020) (Online Resource 2). Aligning with the EAT-Lancet diet would require a global shift towards a much greater consumption of plant-based foods and a lower consumption of ASFs and especially red meat, in particular. In countries where ASFs are consumed in very low amounts (such as LMICs in sub-Saharan Africa and South Asia), increased consumption of ASFs could be beneficial for health (enhancing bioavailable micronutrients and high-quality protein in the diet). Optimal dietary patterns that align with sustainability and health goals vary considerably between countries depending on how and where foods are produced. This asks for a nuanced approach that includes acceptance that the need to ensure adequate intake for chronically undernourished populations will mean an increase in environmental impacts (GLOPAN, 2020; Kim et al., 2020a, 2020b) and that in LMIC settings there are consumer segments with consumption patterns like HICs who would do well to reduce their consumption of ASF for the sake of greenhouse gas reduction (Latino et al., 2020).

\subsection{Food system types and dietary gaps ${ }^{2}$}

The Food Systems Dashboard (Fanzo et al., 2020) defines five food system types (rural and traditional; informal and expanding; emerging and diversifying; modernizing and formalizing; and industrialized and consolidated), based on a composite of four indicators: agriculture value added per worker (a measure of productivity - the ratio between value added in agriculture and number of people employed in agriculture); share of dietary energy from cereals, roots, and tubers; number of supermarkets per 100,000 population; and the proportion of a population that is urban (Online Resource 4). The food system

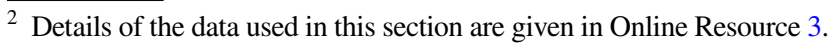




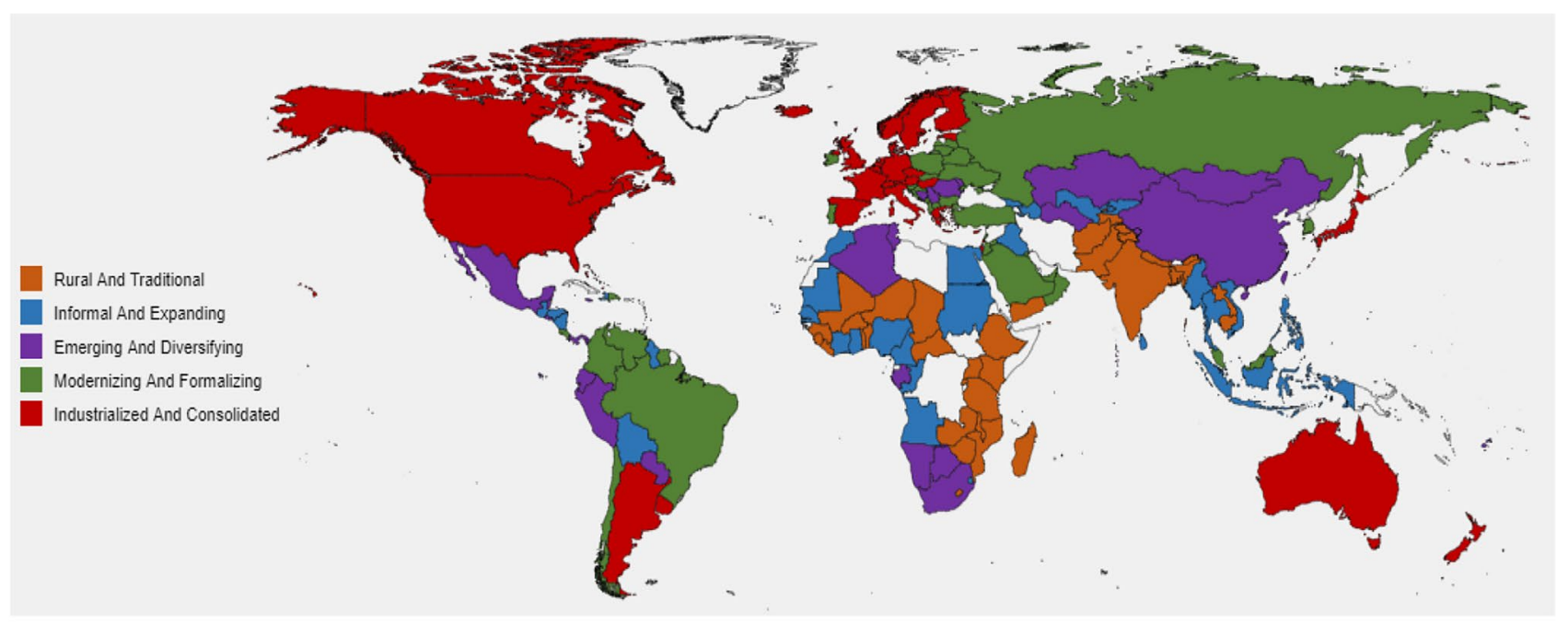

Fig. 1 Countries by food systems type

types correspond to a large extent to income group as also the 2020 SOFI report shows that the percent share of dietary energy available from cereals, roots and tubers decreases dramatically with income group, with low and lower middleincome countries relying more on staple foods than highincome countries (FAO et al., 2020). However, many (but not all) high income countries have industrial and consolidated food systems, whereas middle income countries tend to have heterogenous food system types and most (but not all) lowincome countries have rural and traditional food systems. In addition, single countries can house different food system typologies in their urban and rural areas.The food systems typology demonstrates heterogeneity across regions (Fig. 1) with Africa having four of the five types, Asia representing all five types, Europe with three types, and North and South America with three and four types respectively.

\subsubsection{Consumption of healthy and unhealthy foods per food systems type}

The 2020 State of the Food Security and Nutrition in the World (SOFI) report shows that the supply of cereals and pulses is largest in low and lower-middle income countries compared to wealthier ones (FAO et al., 2020). By contrast, availability of fish, meat, sugar and oil is greater in the high and upper-middle income countries (Online Resource 5). Demand for ASFs has been increasing alongside rising incomes.

Analysis of modeled consumption patterns of healthier versus less healthy food groups by food systems type confirms this picture. Certain elements of a higher-quality diet, such as consumption of whole grains and pulses appear in more 'rural and informal' food systems types, while consumption of fruits and vegetables peak in the 'emerging and industrializing' food system types (Fig. 2). Across all food systems, the average per capita modeled diet does not reach the WHO recommendation of $400 \mathrm{~g} /$ day of fruit and vegetables and the consumption of whole grains is also estimated to be much lower than globally recommended amounts (100-232 g/day, Online Resource 1) in any food system type. Factors related to the food system type, such as less industrial processing and more local and home-processing (hand pounding, local milling), more fragmented distribution channels, and more local marketing are likely contributing factors. While the picture for fruits, vegetables, wholegrains and pulses varies across food system types, clear patterns of increased consumption of red meat, processed meat, and SSBs, which are associated with health risks, are seen (Fig. 3). These foods are further referred to as unhealthy foods.

As populations shift consumption away from cereals and starchy crops, diets tend to become more varied, both in terms of healthy and unhealthy items. Intakes of nutrient-dense foods such as fruits and vegetables, dairy, poultry and fish tend to increase, reflected in terms of higher dietary diversity/variety and also nutrient adequacy (intake of (bioavailable) essential vitamins and minerals improves). On the other hand, boundaries related to moderation, especially in terms of SSBs and processed meats are exceeded. Although we do not have consumption data for UPFs, sales data show an increase in the types and quantities of UPFs sold worldwide, most rapidly in LMICs. This trend is closely related to the industrialization of food systems, technological change and globalization, market growth, political activities of transnational food corporations, and inadequate policies to protect nutrition in these new contexts (Baker et al., 2020). In general, UPFs contain more sugar, salt and fat, including saturated fat. UPFs also facilitate overeating (Hall et al., 2019), 
Fig. 2 Mean daily estimated consumption of vegetables, fruits, whole grains, and pulses by food systems type (g/person/ day). Source: Adapted from Food Systems Dashboard, using GBD data, available at https:// foodsystemsdashboard.org/

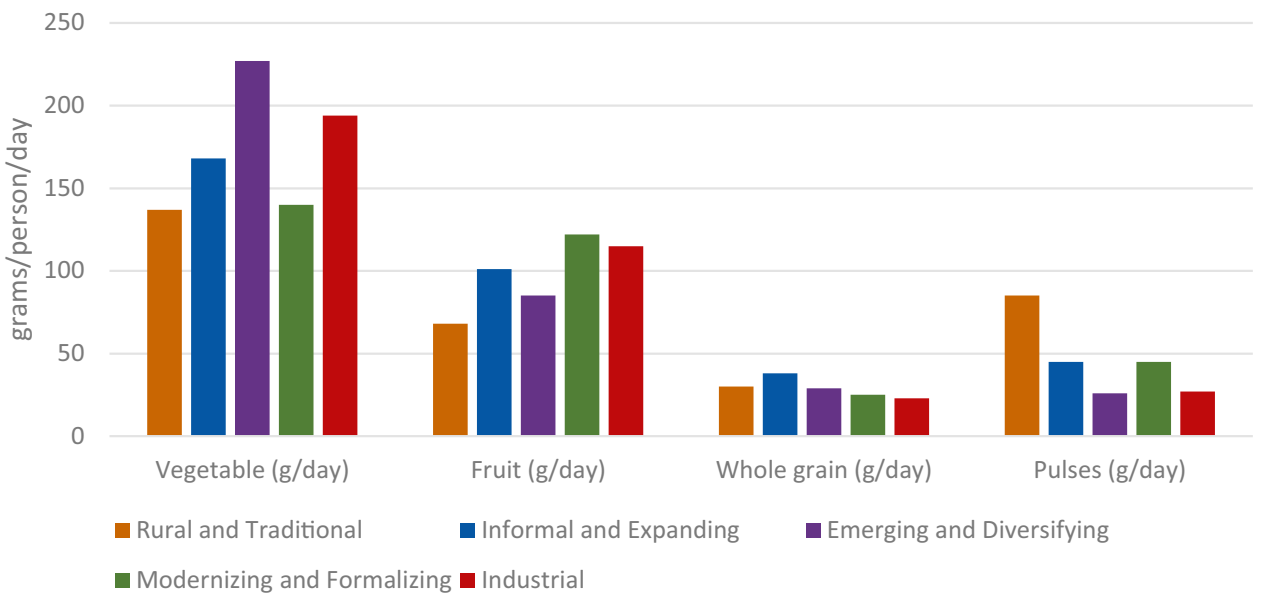

and increased consumption is associated with poor dietary outcomes and NCD risk outcomes worldwide, including in Africa (Reardon et al., 2021) (see Sect. 3.1). Table 1 shows a summary of adherence to WHO-recommended intake levels (Online Resource 1) for the different food systems types.

\section{Food environments, consumer challenges and trade-offs for achieving healthy and sustainable diets}

Striving towards healthier diets requires an enabling food environment which is conducive to the adoption of healthy, safe and sustainable diets by consumers. Food systems are dynamic and constantly evolving and may represent characteristics of different types at the same time. Consumer choices are influenced by the physical, socio-economic and cultural structure of the food environment and the existing policies and regulations affecting the food environment, but are also profoundly determined by individual preferences and perceived challenges and benefits. The challenges of such a dynamic situation necessitate managing trade-offs across and within the different components of food system and between expected outcomes of behavior (for example diets that are healthy or sustainable or affordable). Also trade-offs within the food environment component (i.e. availability, cost, convenience), and between the interests of the different food system actors (such as farmers, food industry, governments, consumers) need to be addressed. In addition, potential synergies should be actively be identified and strengthened. A better understanding of the food environment and of the drivers of consumer food choices will contribute to the identification and implementation of effective interventions across food systems leading to healthy and sustainable diets.

\subsection{Challenges in the food environment}

Several definitions of the food environment exist (Downs et al., 2020; Herforth \& Ahmed, 2015; Turner et al., 2018), but only the definition by Downs et al. (2020) considers
Fig. 3 Mean estimated daily consumption of red meat, processed meat and sugar sweetened beverages (SBB) by food systems type ( $\mathrm{g} /$ person/ day). Source: Adapted from Food Systems Dashboard, using GBD data, available at https:// foodsystemsdashboard.org/

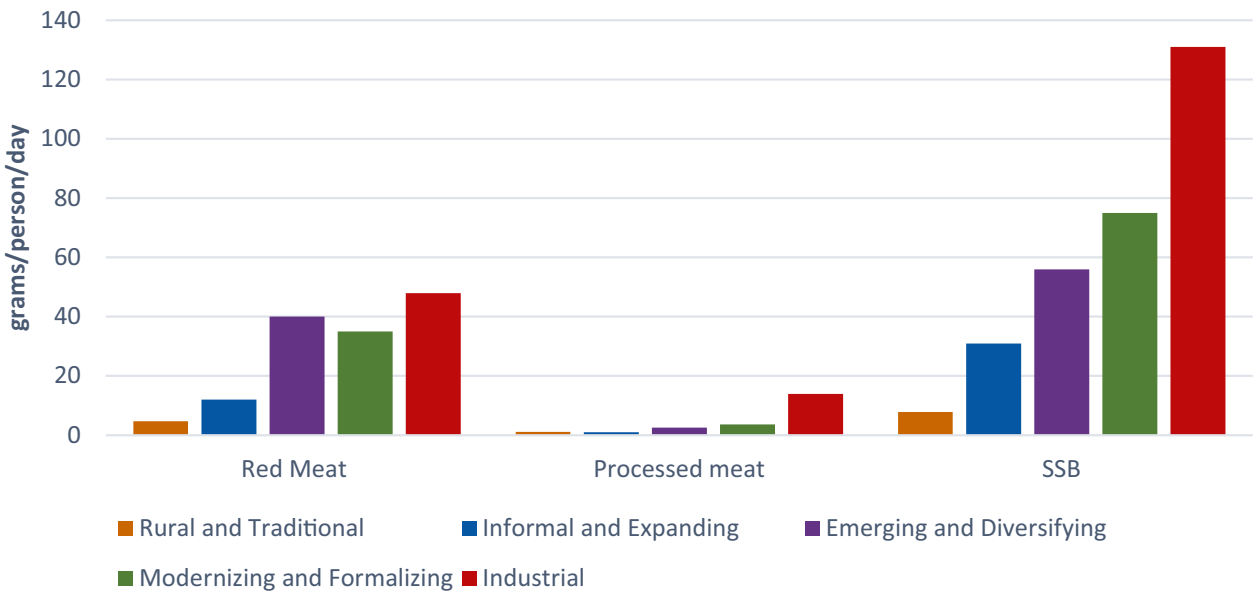


Table 1 Diets meeting WHO-recommended targets for healthy and unhealthy foods in different food systems types

\begin{tabular}{|l|l|l|l|l|l|}
\hline \multirow{2}{*}{} & \multicolumn{5}{|c|}{ Food system types } \\
\cline { 2 - 6 } & $\begin{array}{l}\text { Rural and } \\
\text { traditional }\end{array}$ & $\begin{array}{l}\text { Informal and } \\
\text { expanding }\end{array}$ & $\begin{array}{l}\text { Emerging and } \\
\text { diversifying }\end{array}$ & $\begin{array}{l}\text { Modernizing } \\
\text { and formalizing }\end{array}$ & $\begin{array}{l}\text { Industrial and } \\
\text { consolidated }\end{array}$ \\
\hline Fruits $^{\mathrm{a}}$ & & & & & \\
\hline Vegetables $^{\mathrm{a}}$ & & & & & \\
\hline Whole grains $^{\mathrm{a}}$ & & & & & \\
\hline Pulses $^{\mathrm{a}}$ & & & & & \\
\hline Red meat $^{\mathrm{b}}$ & & & & & \\
\hline${\text { Processed } \text { meat }^{\mathrm{b}}}$ & & & & & \\
\hline SSBs $^{\mathrm{b}}$ & & & & & \\
\hline
\end{tabular}

For definitions of food systems types see Fanzo et al. (2020) and Online Resource 3; ${ }^{\mathrm{a}}$ Colors indicate adherence to WHO intake recommendations (WHO, 2018)—green: above recommended intake; yellow: above 50\% of recommended intake; red: below 50\% of recommended intake; ${ }^{\mathrm{b}}$ Colors for foods that should be consumed either with moderation or not at all indicate above $50 \%$ of recommended intake (yellow) or above recommended intake (red). Source: Adapted from Food System Dashboard, using GBD data, available at https://foodsystemsdashboard.org/

the sustainability properties of foods and beverages: "The consumer interface with the food systems that encompasses the availability, affordability, convenience, promotion and quality, and sustainability of foods and beverages in wild, cultivated, and built spaces that are influenced by the sociocultural and political environment and ecosystems within which they are embedded" (Downs et al., 2020). In this socioecological model, the food environment is the larger piece (characterized by availability, affordability, convenience, promotion, quality), and individual factors interact with it to determine food choices. Food environments include natural (wild and cultivated) as well as built environments (Downs et al., 2020). Wild food environments include forests and jungles, disturbed habitat, open pastures, and aquatic areas, while cultivated food environments comprise food production for own-household consumption. Built or retail food environments include informal and formal markets.

Food environments have different characteristics in the food system types as described in Sect. 2 (Online Resource 2 and Fig. 1). For example, in predominantly rural and traditional food systems, populations mainly rely on the cultivated food environment, and only partially on wild food environments. They also increasingly make use of informal food markets, small shops and street vendors. With urbanization, agricultural intensification and increased agricultural production, food systems transition from 'informal and expanding' towards 'emerging and diversifying', which coincides with an increase in the built food environment (initially informal markets, eventually supermarkets and fast-food chains), while the role of the cultivated environment is reduced. Though these changes impact urban middle-class populations more, rural areas are also impacted with an increasing availability of processed and UPFs (Reardon et al., 2021). This food environment transition is associated with Popkin's et al. (2020) five patterns of nutrition transition moving from hunter gather societies, through agrarian societies and developed urban societies, to societies with concerns for sustainable diets and planetary health (Downs et al., 2020). These patterns are associated with shifts in dietary patterns and physical activity levels and are related to a transition from receding famine to domination by obesity and diet-related NCDs.

Despite a recent increase in the number of studies measuring food environments in LMICs, evidence on relationships between food environments and diets or health is limited, and most studies focus on the evolving built environment rather than wild or cultivated food environments (Turner et al., 2020). This section, therefore, mainly addresses the challenges encountered in measuring the built food environment and its associations with diets and health, and discusses how physical and economic food environments may shape access to healthy diets.

\subsubsection{Physical aspects of food environments}

Systematic reviews (Cameron et al., 2016; Glanz et al., 2012; Gustafson et al., 2012; Pitt et al., 2017) have shown that consumer food environments, and more specifically food placement, food prominence and shelf labelling, influence food purchases in HICs. A systematic review found that availability of food outlets generally showed a greater influence on adults' dietary purchases and intake than proximity to food outlets (Bivoltsis et al., 2018). A recent Australian study showed that moving to a new neighborhood with more convenience stores and café restaurants was associated with an increase in unhealthy food intake, while a greater percentage of healthy food outlets in the new neighborhood was associated with an increase in healthy food and fruit/vegetable intake (Bivoltsis et al., 2020).

Associations between exposure to unhealthy community food environments and socio-economic position are often found 
(Hilmers et al., 2012; Lovasi et al., 2009; Pinho et al., 2020; Sushil et al., 2017), but the direction of the association depends on the metrics (whether location-based or individual-centered) used (Maguire et al., 2017). While community food environments affect food choices among both high- and low-income population groups, the resources available to higher-income population groups may have a protective effect on eating behavior (Ford \& Dzewaltowski, 2008).

In LMICs, food environments are also changing rapidly with an important increase in supermarkets (Baker \& Friel, 2016; Popkin, 2017; Popkin \& Reardon, 2018), a related decrease in informal or wet markets in some countries (Banwell et al., 2012), and an increase in supply of UPF products and away-from-home eating and snacking (Baker \& Friel, 2014; Popkin \& Reardon, 2018; Vandevijvere et al., 2019b). A recent systematic review identified the main factors influencing dietary behaviors in urban food environments in Africa. 12 out of 77 factors related to physical food environments (factors concerning neighborhood socio-economic status, affordability, eating out-of-home, convenience, availability, and type of food source used), two thirds of factors related to the individual, and nine related to macro-level factors such as food prices and advertising (Osei-Kwasi et al., 2020). While the evidence is limited, preliminary findings from studies in LMICs suggest associations between physical aspects of food environment such as density of, or proximity to, food outlets, and dietary intake or obesity (Dake et al., 2016).

\subsubsection{Economic aspects of food environments}

Food prices are an important determinant of food choices (Darmon \& Drewnowski, 2015) and depend on global commodity prices and local supply and demand. In general, staple foods (wheat, maize, rice, vegetable oil) are cheaper per calorie than fresh, nutrient-dense foods (vegetables, fruits, nuts, ASF, beans, pulses) (Darmon \& Drewnowski, 2015; Mendoza et al., 2017). These relative prices help explain why the diets of the poor are often high in starchy staples and lack diversity. The poorest households in LMICs spend 50-80\% of their total expenditure on food (63\% on average) (Herforth et al., 2020), with most purchases directed toward staple grains, some condiments, vegetables, and affordable sources of animal protein such as dried fish (Brinkman et al., 2010). ${ }^{3}$ While being producers, few rural farmer households are self-sufficient and food purchases account for a large part of food consumed (Sibhatu \& Qaim, 2018), and retail prices of most nutrient-dense non-staples are extremely important.

\footnotetext{
${ }^{3}$ In contrast, American households in the highest income quintile only spend $8.2 \%$ of disposable income on food, while household in the lowest quintile spend 35\% of their income on food (USDA Economic Research Service, 2019).
}

While healthy diets are expensive, largely owing to the high absolute and relative prices of non-starchy staples and seasonal effects (Bai et al., 2020), nutrient-poor foods such as starchy staples and UPFs are relatively cheap, and compete for budget share - and diet share - in all countries including LICs (see Box 1). Relative food prices partially explain differences across countries in the prevalence of undernutrition and overweight among adults (Headey \& Alderman, 2019). For example, the combination of high food prices and reduced incomes during the economic crisis in the late 1990s led to an increase in child anemia in Indonesia (Block et al., 2004). Compared to unprocessed and minimally processed foods, UPFs are generally cheaper per calorie (Gupta et al., 2019), being more affordable for low-income households (Colchero et al., 2019). In Brazil an inverse association was found between the price of UPFs and the prevalence of overweight and obesity, mainly in the lowest socio-economic status population (Passos et al., 2020).

Box 1: Cost and affordability of healthy diets and relationship to sustainability

The most recent SOFI report (FAO et al., 2020) showed that healthy diets in 2017 were unaffordable for more than 3 billion people in the world, and most of these people live in Africa and Asia. In Asian countries, 9-50\% of income is spent on food, and in nonconflict-affected African countries it is 25-158\% (WFP, 2017). Mathematical modelling in Brazil, Ethiopia, Ghana, Malaysia and Mexico also found healthy diets more expensive than current (less healthy) diets (Gurmu et al., 2019; Mendoza et al., 2017; Nykänen et al., 2018; Pondor et al., 2017; Verly et al., 2020). On average globally, the range of costs of a healthy diet that meets FBDGs is between USD 3.27-4.57 per day, depending on the specific constraints of guideline applied (Herforth et al., 2020). This is $60 \%$ higher than the cost of meeting nutrient needs only (without meeting recommended food group amounts within FBDGs), and almost five times the cost of meeting energy needs through a basic starchy staple. The cost of a healthy diet exceeds national average food expenditures in most countries in the global South, and exceeds the international poverty line (FAO et al., 2020; Herforth et al., 2020)

The cost of the EAT-Lancet reference diet (Willett et al., 2019) was found to be similarly unaffordable to many (Herforth et al., 2020; Hirvonen et al., 2020). In general, a more sustainable diet is cheaper because reducing the consumption of ASFs generally lowers both the cost and environmental impacts of diets (FAO et al., 2020; GLOPAN, 2020; Springmann et al., 2020). In LICs, most ASFs are relatively expensive (Headey \& Alderman, 2019). A least-cost healthy diet includes ASFs in amounts above the current consumption among many rural populations in LMICs, but in amounts much lower than current consumption in HICs (Willett et al., 2019). Increases in ASFs will be needed to meet dietary needs in LMICs (FAO et al., 2020) and consequent GHGEs need to be offset by reductions of ASFs in HICs to recommended levels (Online Resource 1)

\subsubsection{Convenience aspects of food environments}

Price and affordability have been identified as key factors that determine food choice of low-income populations, whereas 
convenience has been expected to be more important than price for high-income consumers (Ares et al., 2017; Gama et al., 2018; Kearney, 2010). However, it is likely that convenience has been under-recognized as a driver of food choice among people of all income levels, both in rural and urban populations (Herforth \& Ahmed, 2015). The concept of convenience includes the time costs and effort costs spent in purchasing, preparing, cooking and eating (Jackson \& Viehoff, 2016). Finding a balance between monetary and convenience costs was an important consideration among Ghanaian mothers when choosing complementary foods; they reported balancing the costs, concerns for their child's health, and convenience of preparation to reduce demand on their time (Pelto \& Armar-Klemesu, 2011). In New Zealand healthier home-made and home-assembled meals were cheaper options than takeaways in terms of money, but became more expensive when the cost of time was added (Mackay et al., 2017). Present food environments are conducive for the physical and economic access to UPFs. Being low cost, highly palatable and convenient, UPFs offer a high desirability to consumers in the short term, which however has huge trade-offs for longterm health (Box 2).

Box 2: UPFs: consumer trade-offs regarding convenience and taste versus health

UPFs and SBBs have been characterized as hyper-palatable and quasi-addictive (because they are high in fat and saturated sugar or salt) and are often ready-to-eat or ready-to-drink and so highly convenient when food preparation time or storage are an issue. UPFs are cheap and omni-present, sold by street-vendors, in supermarkets, and school and work environments. Consumers appreciate UPFs for their low price, palatability and convenience

Thanks to consumer appreciation, ready-to-eat UPFs contribute to more than $50 \%$ of total energy intake in some HICs (Martínez Steele et al., 2017; Neri et al., 2019, Moubarac et al., 2013) and their consumption is increasing rapidly in middle-income countries (MIC) (Baker \& Friel, 2016; Marrón-Ponce et al., 2018; Martins et al., 2013). Over the past 15 years (2002-2016) UPFs volume sales increased by $67.3 \%$ in South and South-East Asia, $57.6 \%$ in North Africa and the Middle East, while volume sales of ultraprocessed drinks increased by $120 \%$ in South and South-East Asia and $70.7 \%$ in Africa (Vandevijvere et al., 2019b). Though urbanization is a key driver of UPFs consumption, these products have also become an important part of the rural diet. Several studies find that rural populations, while keeping some of their traditional food practices, are transitioning to a Western diet high in ultra-processed and non-local foods (Cattafesta et al., 2020; Fernández, 2020). Reardon et al. (2014) found that highly-processed foods comprised between 13 and $22 \%$ of total food expenditure in rural households in four low- and middle-income Asian countries compared to $17.7 \%$ and $36.7 \%$ in urban households (Reardon et al., 2014). A small study in overweight Brazilian children showed a tendency of higher consumption of added sugar as well as UPF products among those children diagnosed with food addiction (Filgueiras et al., 2019). Other investigators have previously argued that specific components of processed food, and in particular those in "fast food", are addictive in a manner similar to some drugs (Lustig, 2020)
Evidence suggests a strong relationship between the type, intensity and purpose of food processing, diet quality and human health in Latin America (Monteiro et al., 2019) and in Africa (Reardon et al., 2021). In studies conducted in HICs and MICs, consumption of UPFs has been associated with unhealthy dietary patterns (Adams \& White, 2015; Bielemann et al., 2015; Martínez Steele et al., 2017; Moubarac et al., 2017; Batal et al., 2018; Chen et al., 2018; Cornwell et al., 2018; da Costa Louzada et al., 2018; Vandevijvere et al., 2019a; Cediel et al., 2020), lower intakes of most micronutrients (da Costa Louzada et al., 2015; Cornwell et al., 2018; Da Costa Louzada et al., 2018), and overweight and obesity (Canella et al., 2014; Canhada et al., 2020; Mendonça et al., 2016; Monteiro et al., 2018; PAHO, 2015). In several prospective studies, increased consumption of UPFs has been associated with increased risk of depressive symptoms (Adjibade et al., 2019; Gómez-Donoso et al., 2020), higher all-cause mortality (Blanco-Rojo et al., 2019), higher cancer risk (Fiolet et al., 2018; Rico-Campà et al., 2019), higher blood lipids in children (Leffa et al., 2020), hypertension (Mendonça et al., 2017), and cardiovascular diseases (Srour et al., 2019)

\subsubsection{Marketing and promotional aspects of food environments}

In addition to physical and economic food environments, there is convincing evidence that the marketing of unhealthy foods affects food and beverage preferences (Borzekowski \& Robinson, 2001; Boyland et al., , 2011, 2016; Kelly et al., 2015), purchasing requests (Boyland et al., 2016; Buijzen \& Valkenburg, 2003), and consumption (Boyland et al., 2016; Norman et al., 2018). Generally, marketing of foods and beverages, including in LMICs, is predominantly for unhealthy products, as shown in a recent multi-country study (Kelly et al., 2019), and extensively directed to children (Allemandi et al., 2018; Fagerberg et al., 2019; Gamboa-Gamboa et al., 2019; Mallarino et al., 2013; Pulker et al., 2018). In Chile, the country with the most comprehensive policy in place to restrict unhealthy food marketing to children, it was found that preschoolers' exposure to advertising for unhealthy foods, and consumption of unhealthy food products, significantly decreased after the policy was introduced (Jensen et al., 2020; Workicho et al., 2019).

\subsection{Challenges in individual food choices for healthy diets}

Though price and affordability are considered the most important factors for low-income consumers, research indicates that low-income consumers' food choices are also guided by seeking to fulfil higher-order needs related to their desires and aspirations to build social capital, for cultural reasons or to compensate for their limited means (Subrahmanyan \& Gomez-Arias 2008). Research on 
drivers of food choices is abundant for consumers in HICs and MICs but much less is known about consumer choice drivers in LICs. Food choices are influenced by multiple external (cultural and societal) and internal (personal and psychological) factors (Frewer et al., 2001; Kotler \& Armstrong, 2018).

Systematic mapping reviews of determinants of dietary behavior in low- and middle-income urban African populations suggested that similar determinants play a role in food choices as in HICs, at the individual level (income, employment, education level, food knowledge, lifestyle, time), the social environment (family and peer influence, cultural factors), the physical environment (food expenditure, lifestyle), and the macro environment level (Gissing et al., 2017; Osei-Kwasi et al., 2020; Yiga et al., 2020). The ways in which food is being produced, chosen, prepared, eaten or appreciated for its taste are all influenced and defined by culture (Montanari, 2006). Food habits for instance, mainly formed early in life, are culturally determined, though globalization has changed traditional food habits across the world for better and for worse (Kearney, 2010; Raschke \& Cheema, 2008).

Social norms and values have a huge influence on individual food choices. A recent meta-analysis reported that descriptive social norms (what most others do themselves) are more effective in influencing behavior than 'injunctive' norms (what others think one should do) (Melnyk et al., 2019). This research also reported that the effects of social norms on behavior are stronger when they come from groups that are close to the person and when sanctions are specified, whereas explicitly mentioning the rewards of the behavior does not add to the effectiveness of the message. Younger people are also much more influenced by social norms than older people.

Cognitive psychologists and behavioral economists have extensively described how psychological traits influence human behavior: people do not like change (status quo bias), do not like to lose anything (loss aversion), have a strong preference for 'free' products, would rather not make a choice (default bias), prefer immediate over long-term benefits (discounting delayed events) and imitate others (social proof) (Ariely, 2010; Kahneman, 2011). Therefore, the short-term pleasure of consuming an unhealthy food or meal has sometimes more weight than the expected long-term benefit of a healthy diet (Cisneros \& Silva, 2017).

Box 3: ASFs: trade-offs between nutritional value, affordability and environmental sustainability
ASFs have a high nutritional value and are an optimal source of high quality protein, and bioavailable vitamins and minerals (Murphy $\&$ Allen, 2003). Even small amounts of meat, fish or dairy are sufficient to support achievement of adequacy of intake of many nutrients (GBD 2017 Diet Collaborators, 2019). Low consumption of ASFs, combined with high consumption of phytate-rich plantbased foods on the other hand is one of the contributing factors to deficiencies of some micronutrients such as iron deficiency anemia in women in LMICs (Bailey et al., 2015; Kassebaum et al., 2014; Workicho et al., 2019). When consumed in excess, however, ASFs have potentially negative effects on NCDs due to high levels of saturated fat, total energy, salt, and additives, particularly in processed red meat (Micha et al., 2010; Pan et al., 2011).

ASFs are especially important for diet quality in LMICs where diets often have important nutritional gaps and ASFs are less accessible or affordable (Dasi et al., 2019; Grace et al., 2018; Nordhagen et al., 2020). LICs rely more on staple cereals and pulses than HICs, and less on nutrient-dense foods (e.g. ASFs, fruits), as these face high market prices and high price and income elasticity due to demand so that as prices rise, people substitute for these preferred foods (Green et al., 2013; Headey et al., 2017; Abegaz 2018); FAO et al., 2020).

Urbanization is a significant driver of ASF demand around the world, often promoting enhancement in infrastructure like cold chains to allow trade and improve safety in perishable foods. On the other hand, ASF consumption varies with production system and livelihood; pastoralist communities who predominantly rely on livestock often consume more ASFs. In general, however, ASFs are costly and unaffordable for poor households, predisposing them to nutrient deficiencies (Abegaz et al., 2018).

On the other hand, the environmental footprint of livestock is at the heart of heated debates which encourage an important move towards plant-based diets, particularly in HICs (Chai et al., 2019; Willett et al., 2019). There is nevertheless heterogeneity among ASF products (i.e. eggs, dairy, poultry or red meat, and fish) in their nutrient contribution, in their respective production systems and value chains, and in their environmental impact that needs consideration.

Trade-offs offs and synergies between sustainability, affordability, environmental burden, and profitability of production and moderate consumption of ASFs are very context specific (Willett et al., 2019). Key challenges will be to ensure that ASFs are accessible to the most nutritionally vulnerable, putting regenerative production practices into place, and reducing AFS consumption where it is excessive. Important features of these potential compromises between ASF production and consumption are compiled in Online Resource 6.

Though most people like to see themselves as rational human beings making conscious choices, $95 \%$ of behavior is driven by subconscious determinants, which may favor impulsive alternatives that have an immediate benefit (Logue, 1998; Zaltman, 2003). Subconscious motives include status, comfort, fear, disgust, attraction, love, and play amongst others (Aunger \& Curtis, 2013). To achieve behavior change it is therefore insufficient to 
rely only on planned, conscious and rational decisions of consumers, and emotional and subconscious motives that deliver more immediate, though not always rational, benefits should also be tapped into.

Within the framework of this paper, it is key to understand whether other expected outcomes of food systems transformation (sustainability and inclusiveness) could be used to drive consumer food choices for a healthy diet. A European report indicated that sustainability is increasingly mentioned as a motive by consumers who fear for the destruction of the planet and its resources (BEUC, 2020). How strong these drivers are, in comparison with other drivers, especially those seeking shortterm benefits, is unknown and little is known about how consumers in LICs are (or could be) influenced by these drivers.

Trade-offs between sustainability, cost and health are illustrated for ASF (Box 3), which highlights the undisputable role of ASFs in helping nutrient gaps in resource-poor households where consumption is below the recommended minimum levels; but warns against health and environmental risks of overconsumption; and calls for necessary reductions in consumption in high-income settings in LMICs and HICs both for human and planet health. Online Resource 4 summarizes key features of these potential compromises between ASF production and consumption; the features are related to nutrition, health, environmental, social and economic sustainability.

\section{Food systems innovations toward healthy diets}

This section highlights opportunities and innovations that have or could motivate consumers to make healthier food choices and in turn asks how a shift in consumer demand towards healthier foods may drive changes in the built and cultivated food environment. ${ }^{4}$ Rather than starting from the producer perspective, we propose to start with innovations at the consumer level and in food environments where consumers make choices about food purchases. As shown in Sect. 3, there is no universal consumer and drivers of food choices vary widely between individuals at different stages of the life cycle and between population groups, and cultures. Creating awareness on, and filling information gaps in, what healthy diets are will be insufficient to drive consumer choices in food systems transformation. Social and behavior change interventions must do more than rely only on planned, conscious and rational decisions of consumers, and should understand and use emotional and subconscious motives that deliver more immediate, though not always rational, benefits.

\subsection{Consumer-oriented innovations toward healthy diets}

Though hardly an innovation, there is ample evidence of the effectiveness of nutrition-focused social and behavior change communication (SBCC) $)^{5}$ in LMICs, especially to improve infant and young child feeding practices (Benedict et al., 2018; Lamstein et al., 2014; Webb Girard et al., 2020). However, there are few common elements in the design of such interventions, hampering replicability (Graziose et al., 2018), and few SBCC programs have demonstrated impact when implemented at scale. The well-studied Alive and Thrive program demonstrated impact of at-scale implementation in Bangladesh, Ethiopia and Vietnam using interpersonal communication, mass media, and social mobilization and focusing on a limited number of actionable messages (Kim et al., 2020a, 2020b; Menon et al., 2016). A particularly successful example is a television advertisement in Vietnam in which two charming babies deliver the key message that an exclusively breastfed child does not need additional water. ${ }^{6}$ In East Java, Indonesia, the adoption of a set of behavior change interventions incorporating emotive, interactive and surprising ways of improving child feeding was tested as part of an integrated nutrition, hygiene and healthy intervention program, and showed a significant effect on infant and child feeding outcomes (Keats et al., 2019).

School feeding or school nutrition programs are implemented in a large number of countries as they are deemed beneficial for the physical, mental, and psychosocial development of school-age children and adolescents, particularly those in low- and middle-income countries (LMICs). Findings from recent reviews (Kyere et al., 2020; WHO, 2020) suggest that comprehensive school nutrition policies using multiple components and approaches (e.g. diet, physical activity, educational interventions, environmental changes) are associated with positive weight-related, dietary and other outcomes among school children (WHO, 2020), though impact on anthropometry and nutrition behaviour require further investigation (Kyere et al., 2020). Nudging children

\footnotetext{
${ }^{5}$ SBCC interventions can be categorized into three areas: (1) interpersonal communication, (2) use of the media, and (3) community/ social mobilization.

${ }^{6}$ https://www.youtube.com/watch?v=-wIWFlr3xNE
} 
toward fruit and vegetable consumption has proven effective through the provision of free fruits and vegetables in school settings (Nguyen et al., 2020) or the use of smiley stamps as motivational incentives (Gwozdz et al., 2020). A recent systematic review and meta-analysis assessed the effectiveness of interventions on the food environment within and around schools to improve dietary intake and prevent childhood obesity (Pineda et al., 2021). Interventions had a significant and meaningful effect on BMI z score (standard mean difference: $-0.12,95 \%$ CI: $0.15,0.10$ ) and fruit consumption (portions per day, standard mean difference: $+0.19,95 \%$ CI: $0.16,0.22)$ but not on vegetable intake. Changes in the school food environment could improve children's dietary behavior and BMI, but policy actions are needed to improve surrounding school food environments to sustain healthy dietary intake and BMI.

Much less is known about fostering healthy diet choices of other population groups (households, women, adolescents, primary school children) in LMICs. The bulk of the evidence on impact of consumer motives, individual behavior and social norms on diet and nutrition comes from HICs in the global North. Most innovative approaches make use of nudging strategies ${ }^{7}$ such as use of social norms, digital technology and social media, which complement more traditional inter-personal and mass-media behavior change approaches.

\subsubsection{Leveraging social norms to motivate healthy diets}

Social norms, defined by culture and context around healthy eating, may influence an individual's food choice, implying that a code exists for appropriate behavior. Well-known social norms and taboos exist in LMICs for instance around nutrition for young children (for example avoiding eggs), and pregnant and lactating women. ${ }^{8}$ Social norms can be asserted by key influencers including parents and family, friends and peers, health care professionals, school teachers, the elderly, and traditional and religious leaders. Influencers may also be role models in society, such as singers, actors, or on social media (Instagram, YouTube, bloggers). Family traditions and the way parents talk about food, cook meals and eat together have been demonstrated to have a huge influence on the healthy eating habits that a child develops as documented in studies in HICs (Walton et al., 2018; Weinstein, 2005).

A review of 15 experimental studies in HICs found consistent evidence that norms influence food choices:

\footnotetext{
7 Nudges are any aspect of choice architecture altering behavior in a predictable way without forbidding any options or significantly changing their economic incentives. To be considered a mere nudge, the intervention must be easy and cheap to avoid, and not mandatory (Thaler and Sunstein 2008).

${ }^{8}$ https://sightandlife.org/wp-content/uploads/2017/02/Food-Taboosinfographic.pdf
}

information indicating that people not known to participants (e.g. 'other students' and 'other people in the UK') making low- or high-energy food choices, significantly increased the likelihood that participants made similar choices (Robinson et al., 2014b). In an experimental setting, messages containing reference to fruit and vegetable consumption of peers also proved to be more effective than a general health benefit statement (Robinson et al., 2014a). Draper et al. (2015) reviewed 30 studies to determine the impact of social norms and social support on diet, physical activity and sedentary behavior of adolescents and found sufficient evidence for parental influences, especially on diet, but much less conclusive evidence for peer influences (Draper et al., 2015).

Although no literature was found that describes the use of social norms to influence healthy eating consumer behavior in low-income populations, a large body of literature describes the importance of cultural preferences and taboos in LICs and the use of positive deviance approaches to influence nutrition behavior (D'Alimonte et al., 2016; Fowles et al., 2005). A few LMIC examples include a mass-media and community-based behavior change campaign in Indonesia. The intervention used of the concept of gossip (reflecting social pressure) to reinforce appropriate infant feeding practices, successfully impacting dietary diversity (vegetable intake) and breastfeeding, but not snacking behavior (White et al., 2016).

\subsubsection{Digital interventions and social media}

Digital interventions have become mainstream for lifestyle behavior change regarding healthy eating, physical activity and quitting smoking in the global North. A review of online interventions indicated that the most successful techniques in achieving dietary behavior change are goal setting, self-monitoring, and providing instructions and feedback. However, the quality of the evaluations was in general moderate with relatively small sample sizes, a lack of effective engagement measures, and not all studies reported attrition rates (Young et al., 2019). Another review provided modest evidence that app-based interventions to improve diet, physical activity and sedentary behaviors can be effective, especially when apps are used in conjunction with other intervention strategies (such as counselling sessions, motivational emails, or pedometer use) which appear to be more effective than stand-alone app interventions (Schoeppe et al., 2016). Another systematic review on the use of social media for the delivery of health promotion on smoking, nutrition (weight loss but not healthy diet), and physical activity, concluded that there was insufficient quality evidence to establish whether health promotion delivered using social media was effective in improving health (Johns et al., 2017).

Several studies reported on the influence of social media on both positive and negative dietary habits of HIC adolescents and young adults (Chau et al., 2018; Fleming-Milici \& Harris, 
2020; Hsu et al., 2018). No literature was found with evidence for LICs, though examples of use of social media exist. ${ }^{9}$

\subsection{3 m-Nutrition services}

Over the past 5-10 years, the use of mobile phone technology targeting behavior change has increased globally, with expectations to facilitate the adoption and long-term maintenance of new behaviors. Increased coverage of mobile broadband and rising adoption of mobile phones has catalyzed the development of $\mathrm{m}$-Health, $\mathrm{m}$-Nutrition, and $\mathrm{m}$-Agri services. These services can be relevant for both urban and rural consumers in most LMICs, though need contextualization and innovation to reach women and the very poor for whom accessibility and connectivity remain key challenges. Further challenges include modest evidence on impacts, a lack of sustainable business models, and ineffectiveness of push messages (Barnett et al., 2016).

A review of $15 \mathrm{~m}$-Health studies in Asian and Latin American countries showed that $50 \%$ of the e- and $\mathrm{m}$-Health interventions were effective in increasing physical activity, and $70 \%$ of the identified interventions were effective in improving diet quality (Müller et al., 2016). However, an evaluation of m-Nutrition services in Ghana and Tanzania found such services did not always reach very poor households, nor women, and had a limited effect on nutrition behaviors at scale, though active users reported some behavioral change. Stand-alone mobile phone nutrition services may be insufficient to motivate behavioral change, but may be more effective if combined with in-person support (Barnett et al., 2020). There are also important coverage and usage gaps. The widest gaps are in sub-Saharan Africa where $31 \%$ and $45 \%$ of the population experience a coverage and a usage gap respectively versus $10 \%$ and $43 \%$ of the global population (GSMA, 2019). Significant technology investments, innovations and emerging business models aim to close these gaps.

\subsubsection{Social marketing by the private sector}

Evidence exists of the success of social marketing advertisements on healthy eating (Abril \& Dempsey, 2019). Campaigns with both stop-and-go outcomes (such as swapping fast food for healthy choices) as well as generic outcomes (such as using a coach for support in weight loss) were more successful than campaigns with simple stop-or-go outcomes (such as decreasing fast food consumption). The length of campaigns (longer than 6 months) was also identified as a critical success factor. Private sector food companies are now also investing in healthy choice campaigns, not only in HICs but also in LMICs (for example Green Food Steps in Nigeria, Nutrimenu

\footnotetext{
${ }^{9}$ See for example https://www.smartfood.org
}

in Indonesia ${ }^{10}$ ). Though the impact of such interventions is rarely assessed, a study in Nigeria indicated that a social marketing approach to behavior change increased the amount of green leafy vegetables added to stews and iron-fortified cubes added to soups (Lion et al., 2018).

With the objective of transforming food systems towards healthy diets, a healthy planet, and healthy livelihoods for workers along the food value chain, it is key to take consumer motives, including psychological and emotional traits, and social norms, into consideration to create demand for healthier food options. Innovations and approaches for which evidence is currently mainly based on the global North offer entry points to develop context-specific innovations in the global South for both urban and rural populations. Rural areas in LMICs are increasingly connected through mobile and digital technology and packaged and processed foods are increasingly part of the rural diet. Consumers should be considered as active drivers in the transition of food systems, and not only as passive recipients at the end of the food value chain.

\subsection{Market oriented innovation pathways toward healthy diets}

\subsubsection{Food labelling interventions}

Providing nutrition information on packaged food products is mandatory in most HICs, but it is not as common in LMICs. Labels can potentially improve health through a direct effect, by reducing consumer demand for less healthy products; or through an indirect effect, by influencing manufacturers or restaurants to reformulate their products so that they meet the requirements to receive a positive label, which makes them becoming more attractive for consumers to buy.

When labelling is mandatory, all packaged foods need to provide nutritional information. Labels usually list calories, fat and protein content, and some micronutrients, mostly in a table on the back of the pack (BOP).${ }^{11}$ However, in several countries new front of packaging (FOP) labeling has been implemented. In Latin America, however, several countries have introduced an FOP "stop sign" type system. Labelling can be voluntary, providing a signal for foods that are healthier when the food product meets standards set by an external agency. For example, the Nutriscore FOP label in France

\footnotetext{
$\overline{10}$ See https://www.knorr.com/ng/a-world-of-flavour/about-us/greenfood-steps.html and https://www.royco.co.id/royconutrimenu.html

11 BOP labelling is a nutrition declaration on pre-packed foods providing the energy value, amounts of fat, saturates, carbohydrate, sugars, protein and salt per $100 \mathrm{~g}$ or per $100 \mathrm{ml}$ of the food, in either a legible or linear tabular format. FOP nutrition labelling is simplified nutrition information on the front of packages aiming to help consumers with their food choices.
} 
is voluntary; though it began adoption in 2018, now about $50 \%$ of foods use it. In Asia, examples include the introduction of a warning statement in Indonesia, and a red label for soft drinks with high sugar contents in Sri Lanka. Several Asian countries use FOP health logos such as the healthier choice symbol (Malaysia and Thailand), the Wise Eat logo (Philippines), or a logo based on the Healthy Choices system. Finally, South Africa has introduced a voluntary traffic light label for energy, total sugar, fat, saturated fat and total sodium or salt equivalent per serving.

Although there is no evidence on the impact of voluntary labelling efforts on public health and diets, evidence exists on mandatory FOP labelling or labelling on restaurant menus in HICs. A meta-analysis concluded that FOP food labels increased the percentage of people selecting a healthier food product by about 18\%, but the impact on energy intake reduction was not statistically significant (Cecchini \& Warin, 2016). The same study indicated interpretive traffic light labels seem to be slightly more effective than Guidelines on Daily Amounts or other type of FOP labels, in which green labels suggest healthier foods. A more recent meta-analysis suggests that labelling reduces energy and fat intake among consumers, and increases vegetable intake (Shangguan et al., 2019). Restaurant labelling may not be as effective. Long et al. (2015) found that menu labelling of calories appears to lead to a decline of $18 \mathrm{cal}$ in the total calories ordered on average, but they point to significant heterogeneity across studies.

Evidence exists on several of the FOP labelling programs in Latin America. In Chile, a black stop sign is used to indicate foods high in salt, added sugar, calories, or saturated fats (Reyes et al., 2019). Araya et al. (2020) found that consumers tend to substitute away from breakfast cereals with black labels (towards those without labels), but found no effect on purchases of chocolate or cookies. There is also evidence of product reformulation to avoid black labels (Reyes et al., 2020). No studies appear to exist on longerterm impacts or health impacts of food labelling, but some evidence shows SSB demand has fallen following labelling (Taillie et al., 2020). In Mexico, Vargas-Meza et al. (2019) demonstrated that directive and semi-directive labels, such as warning labels, health star ratings or traffic light style labels, may be better at helping low- and middle income consumers make healthier food choices than non-directive FOPs, such as Guidelines on Daily Amounts (Vargas-Meza et al., 2019).

Beyond HICs and recent evidence from Latin America, further evidence of the impact of labelling on healthy food choices remains limited. A review of nutrition labelling studies in the global South indicates that consumers like to have nutrition labelling on pre-packaged foods, but use and comprehension of the labels is low (Mandle et al., 2015). The same review concluded that government-endorsed nutrition information that is clear, easily visible, standardized, and includes symbols or pictures, are positively received by consumers. A qualitative study in South Africa found that food prices remain a more important consideration among South African consumers when selecting food products than quality and nutritional value (Koen et al., 2018).

\subsubsection{Advertising regulation}

Countries aim to regulate either food advertising or packaging. Limiting advertising of junk foods is used to reduce consumption of those foods. This is considered particularly important for advertising directed at children in order to reduce consumption and curb the rise in child obesity. Evidence on such interventions is mixed but suggests mandatory bans could be more effective than self-regulation. Quebec banned advertising to children between 1984 and 1992. Dhar and Baylis (2011) compared households in Quebec and neighboring parts of Ontario, and found that the ban on advertising targeted to children decreased the propensity of consumers to purchase fast food (Dhar \& Baylis, 2011). A systematic review combining studies on actual and self-regulation suggests that more actual regulation of food advertising targeted to children was more effective at reducing children's exposure and had more potential to improve health than self-regulation (Chambers et al., 2015). Currently, 16 countries have implemented regulations on unhealthy food marketing to children, including both restrictions on television advertising during children's programming, and restrictions on advertisements in schools (Taillie et al., 2019).

\subsubsection{Changes in default options and changes to the physical environment}

As people are, in general, risk averse and prefer the status quo, the default option is an important element of decisionmaking (Ariely, 2010; Kahneman, 2011). Setting healthy options as default in food choices may work well in fast food and institutional restaurants (workplaces, schools) (Anzman-Frasca et al., 2015; Thorndike et al., 2012). Public procurement schemes such as 'home-grown' school feeding programs, can also complement regular food baskets with fresh food, such as vegetables and eggs, purchased from local smallholder farmers (Masset \& Gelli, 2013).

The proximity of healthy foods also encourages its consumption by low-income populations, who often lack the time to prepare healthy dishes or do not have refrigeration to store and preserve healthy perishable foods. In Madagascar, 'baby restaurants' promote and sell nutritious locally-made complementary foods for children over 6 months of age, and mobile food vendors sell healthy porridges door-to-door (MQSUN+, 2018). Similarly, fruit and vegetable cart interventions have 
been attempted in contexts as varied as New York City and Nigeria. In New York City, a mobile vending initiative was associated with an increase in the number of establishments selling fruits and vegetables in intervention neighborhoods relative to control neighborhoods (Farley et al., 2015). In Ibadan, Nigeria, a vegetable-on-wheels intervention has similarly attempted to increase availability and convenience by setting up carts that offer ready-to-cook vegetables. In both cases, the interventions were simply proof-of-concept and there is no robust evidence that they actually affected diets.

Further innovations relate to making healthy foods more convenient. Milk vending machines in Kenya reach a growing market segment of consumers, allowing them to buy the exact amount of milk they need, when they need it, and at a much lower cost than processed packaged milk (Ayuya et al., 2020; MQSUN+, 2018). The combination of affordability and convenience is another attractive choice for consumers as in the case of pre-cooked, dehydrated beans that are sold in small, affordable packages by Smart Logistics Solution Ltd., a Kenyan aggregator and marketer of cereals and pulses (MQSUN+, 2018). These solutions, which can potentially be used in both urban and rural areas, provide economic opportunities for the (often female) entrepreneur and potential health benefits for consumers.

\subsubsection{Taxes and subsidies}

Governments can lower the prices of healthier foods, relative to those that are consumed sufficiently or in excess, through subsidizing nutrient-dense foods or by imposing a tax on an unhealthy food component, e.g. the introduction of a sugar or unhealthy fat tax. The outcomes of such interventions for different groups of consumers should be carefully considered to determine direct and indirect effects, such as substitution and economic effects (Jensen \& Smed, 2018). A careful combination of taxes and subsidies is perhaps the most effective option (Redondo et al., 2018).

The most common policy, implemented in 42 countries and eight localities around the world, are taxes on SSBs (Global Food Research Program, 2020) to reduce demand and curb the rising rates of overweight and obesity. Much of the evidence on effects of sugary drink taxes comes from Mexico, a leader in implementing this tax. Colchero et al. (2017) show sales of taxed SSBs fell by 5.5\% in 2014 and $9.7 \%$ in 2015 relative to $2012-2013$, while sales of non-taxed beverages increased by $4 \%$. Simulation evidence suggests that impacts of this magnitude could reduce type 2 diabetes cases by about 190,000 cases over ten years, against a population of over 130 million (Sánchez-Romero et al., 2016). Researchers are now beginning to consider changing the design of taxes to increase impact. Taxing grams of added sugar rather than taxing volume could trigger demand shifts and support product reformulation, thus further benefiting consumer health; a sugar tax rather than a volume tax has been shown to reduce diabetes incidence by a further $0.7 \%$ per year in the US (Grummon et al., 2019). Another frontier for potential taxes would be on UPFs, since they are associated with negative health effects (Pagliai et al., 2020). Taxes on UPFs could reduce demand through price effects; such taxes could also lead to reformulation.

Consumption subsidies for healthy foods are another option that has been used mostly in the form of vouchers for fruits and vegetables. Voucher programs, targeted at low-income consumers in Canada and the US, can be used at farmers' markets for fruits and vegetables (e.g. Byker et al., 2013; Downs \& Fanzo, 2016). There is little evidence regarding their effectiveness in increasing fruit and vegetable intakes, with only two studies showing any effect on intake (Olsho et al., 2016)and food security (Ridberg et al., 2019). Distributing coupons could lead to increased fruit and vegetable intake, and be an effective type of intervention to test in a developing country setting where incomes are low and lack of affordability is a major barrier to consumption.

Last, cash or food transfers (whether conditional or unconditional) offer an opportunity to improve diets among poor and marginalized populations by increasing their purchasing power, improving diet quality and reduce poverty and food insecurity (Hawkes et al., 2020). A recent review focusing on sub-Saharan Africa demonstrates cash transfers typically improve dietary diversity among young children (de Groot et al., 2017). Targeted transfers are more effective than universal transfers in reaching the most vulnerable and reducing programme costs, but might suffer from inclusion and exclusion errors (Hanna \& Olken, 2018). Despite their benefits, there are concerns about unintended negative effects, especially in areas where a nutrition transition is taking place and UPFs are abundant, as in Mexico and the Philippines. These negative effects are related to providing or subsidizing foods, snacks and beverages high in energy, sugar, fat, and salt, or providing income that could be used to purchase these foods, increasing the risk of exacerbating the growing problem of overweight, obesity and the double burden of malnutrition. Cash transfers can potentially be leveraged for double duty through the inclusion of strong education and behaviour change communication focused on healthy diets (Hawkes et al., 2020); if not, particularly in areas with adverse food environments, targeted coupons may be preferable to cash transfers.

\section{Discussion}

This paper argues that taking a healthy diet perspective, instead of a narrower production-focused approach, in food system transformation is essential to reverse current trends towards unhealthy and unsustainable diets and address the 
persistent problems of undernutrition and micronutrient deficiencies and the rapid rises in overweight and obesity and related NCDs. Business as usual in nutrition, health, and food system policies and programs has not been successful at preventing or attenuating the nutrition transition, first mentioned more than 25 years ago by Popkin (1993). The main focus of most large agriculture investments and food system transformation has been on increasing food production, strengthening agri-food supply chains and markets, and focusing on increasing income of producers and value chain agents and ensuring that nations supply enough calories (mostly from traditional staple cereals and oil crops) to meet the needs of their growing populations (Khoury et al., 2014). In parallel, investments in small-scale agriculture, nutrition, and gender programming also gained momentum in the past two decades, reaching populations that were generally left behind by large agriculture investments. These nutrition- and gender-sensitive programs, which mostly targeted rural and underprivileged populations, operated as a type of "safety net" for poor households to increase their agriculture production and consumption diversity, empower women, and improve maternal and child nutrition. Reviews of these programs' impacts showed that they were successful in achieving most of their goals, including improving household production diversity and maternal and child dietary diversity, empowering women, and in some cases increasing maternal knowledge of child feeding practices and health practices. There was, however, little evidence of significant impacts on reductions in child undernutrition (e.g. stunting or wasting), which would have required greater investments from other sectors, especially in health and water and sanitation (Ruel et al., 2018). One of the conclusions from the reviews of this experience is that agriculture should prioritize achieving impacts on what it does best-provide food in the right amount and of the right quality to support consumption of diverse and healthy diets for all household members-rather than focusing more narrowly on achieving gains in child anthropometry (GLOPAN, 2020; Ruel et al., 2018). Achieving healthy diets should be an explicit goal of all sustainable food systems transformation, if the SDGs on food security, nutrition, health, poverty, and education are to be achieved.

Until recently, the food environment, consumer preferences and dietary needs, the whole-of-diet approach, and the affordability of healthy diets were generally neglected in international reports on agriculture and food system strategies (Brouwer et al., 2020). Though the importance of healthy food environments to reduce obesity was highlighted in 2013 by the INFORMAS network (Swinburn et al., 2013), a healthy and sustainable diet was not seen as an explicit goal of global food systems until the publication of the High-Level Panel of Experts on Food Systems and Nutrition (HLPE, 2017), the EAT-Lancet paper on healthy diets from sustainable food systems (Willett et al., 2019), the
SOFI (FAO et al., 2020) and the Global Panel on Agriculture and Food systems for Nutrition Foresight 2.0 (GLOPAN, 2020) reports. Likewise, available information and insights regarding diets, consumer choices and food environment has only recently begun to be included in food systems analysis.

The large heterogeneity between regions and countries, which often house multiple food system types that are dynamic and rapidly evolving, highlight that there is no 'one size fits all' solution. We need a deeper understanding of consumer food choices and the food environment in order to inform transformative food system strategies. In food systems analysis it is often assumed that healthy foods are available and accessible, populations will consume them. This assumption is too simplistic. There is good evidence that consumers living in urbanized areas and other contexts where food systems are complex in HICs and MICs can be nudged into healthier choices by establishing social norms, using digital applications, m-Health services, product labelling, sugar taxes, or making healthy food the default choice. Therefore, demand creation and SBCC strategies should be paired with innovations in the food environment and used to redirect food systems toward healthier diets. Yet, there is limited to no evidence on whether (and how) this will work or of what types of adaptations are needed for food systems in L, or and what the potential for scaling in different contexts is likely to be.

In addition, most interventions targeting the consumer, food environment or supply of nutritious foods are developed as stand-alone interventions, focusing on a single component of food systems. Though such interventions may be effective within their 'food systems component', there is no alignment, cohesion, or connectedness of interventions across components. Improving cohesion of these interventions and combining with policy incentives will enable a multiplier effect of food system transformations on desired health and environmental outcomes at scale. There are however, important challenges for food policies and innovations. Game changing innovations that have the power to transform food systems are unlikely to be stand-along actions but rather collaborative action between business, public and private sector (Pederson et al., 2020). This is not a panacea. Although comprehensive nutrition policies have been developed over the last decades in various countries, these policies are poorly funded (Development Initiatives, 2018), evaluated (Morris et al., 2008) and rarely involve the private sector (Lachat et al., 2013).

To enhance coherence and connectedness, governments are encouraged to develop and implement a National Food Systems Strategy and Action Plan, which addresses desired health, environmental and inclusivity outcomes through cohesive, interconnected interventions across all food system components, and which is aligned with a National Nutrition Strategy and Action Plan. These should include development or revision of national FBDGs that consider not only health impacts of recommended diets, but also environmental impacts and sustainable food 
production. These guidelines set the minimum dietary standards to prevent malnutrition in all its forms and related health risks and facilitate the formulation of dietary targets that should be taken into account together with sustainability and inclusiveness goals in decisions for public and private investment strategies for food systems transformation that contribute to the achievement of healthy diets. Where food based dietary guidelines are present, they are often not used to their full potential and evidence of embedding food based dietary guidelines in policies, programmes and strategies in different sectors (e.g. health, agriculture, education etc.), settings (e.g. schools, communities, workplaces, restaurants, catering) and actors (government, private sector, civil society organisations, media) is scarce (Wijesinha-bettoni et al., 2021). Development of food based dietary guidelines should be accompanied by implementation plans including monitoring and evaluation of progress and impact on healthy diets from sustainable food systems.

To ensure food system transformations will deliver on better health and nutrition, within planetary boundaries and based on a sound social foundation, we recommend that food system analyses and intervention designs incorporate healthy diet considerations. This includes challenging traditional thinking by starting with the consumer and going back along food system processes to the producers to: (1) re-focus food systems transformation towards achieving healthy diets from sustainable food systems; (2) use food systems analysis to identify potential bottlenecks and enablers in the various components, actors and drivers of food systems which prohibit or promote the achievement of healthy diets. Contrary to the traditional supply- and market-oriented food systems analysis, such reverse analysis aims to assess the potential impact of any change or intervention in any given food systems component on the expected healthy diet outcome. To ensure that a healthy diet perspective is taken into consideration in food systems analyses, intervention design and policy development, we recommended that:

1. Food systems analysis contributes to a more in-depth understanding of the availability, accessibility and affordability of healthy diets in each food system type to inform decision-making regarding context-specific food systems policies and interventions.

2. Food systems analysis identifies potentially conflicting or synergistic objectives across, or trade-offs between, multiple food systems actors, drivers and outcomes. Whereas the healthy diets objective seems well aligned with attaining environmental sustainability of food systems, other trade-offs may exist between desired healthy diets among consumers, economic objectives of producers and social objectives of governments, which all need to be weighed and managed carefully.

3. Food systems analysis should include the formulation of questions that challenge intrinsic assumptions regard- ing the relationship between food system components. A specific intervention in one of the components may have unintended consequences in another. These assumptions and consequences should be well understood and made explicit. For example, if behaviour change interventions are successful in catalyzing demand for specific nutritious foods (e.g. fruits and vegetables) and supply cannot increase to meet this demand, prices would increase with potential negative effects on diets among the poor or other disadvantaged populations.

4. Research investments are made in LMICs for testing interventions that are impactful in one food system type and for adoption and effectiveness assessment in another food system, for example nudges to drive healthier consumer choices should be adapted to, and tested in, countries characterized by a rural, traditional and emerging food systems typology.

Finally, complex food systems transformations involving multiple actors, activities and outcomes call for strong food systems governance and political will to provide direction and incentives to explicitly manage potential trade-offs, different or even conflicting interests among food system agents and unintended consequences on targeted outcomes (Brouwer et al., 2020). This governance should involve careful navigation between those agents who have vested interests in the status quo versus those who are promoting incumbent system changes. Coalition forming/organizing social movements that support innovations are crucial to advocate for more accountability across food system governance (Sartas et al., 2020). This also requires the courage to challenge and discuss wellestablished food policies such as subsidies for staple foods or intensive livestock production, and requires interventions that address power imbalances, and connections between formal and informal systems, while giving a voice to marginalized populations (Dunning et al., 2015; Mancini, 2019). The proposed paradigm shift, by adopting reverse thinking and starting from a dietary perspective to food systems transformation is of relevance for the implementation of the actions and gamechanging solutions identified through the Action Tracks and Dialogues towards the United Nation Food System Summit, which may lead to many more innovations being implemented at scale leading to a transformation towards more sustainable and more inclusive food systems that deliver healthier diets.

Supplementary Information The online version contains supplementary material available at https://doi.org/10.1007/s12571-021-01204-5.

Acknowledgements This article is derived from a cornerstone paper which informed chapter 2 and 8 of the International Fund for Agricultural Development Fund (IFAD) Rural Development Report 2021. The authors thank the support of Ms Betuil Uyar from the Division of Human Nutrition and Health, Wageningen University, The Netherlands, 
and Ms Olivia Frost from WRENmedia, Suffolk, United Kingdom, for their support.

Author contributions IB: leading author; MJL: management of author contributions, contributor to $\mathrm{Ch} 3$ and 4 specifically on consumer choices and consumer-oriented innovations; AdB: contributor to food systems innovations, Ch 4; PDS: contributor to Ch 3, specifically animal-sourced foods; JF: overall reviewer and advisor; AH: contributor to $\mathrm{Ch} 2$, especially food-based dietary guidelines and reviewer of $\mathrm{Ch}$ 3 , cost of diet; GK: contributor to $\mathrm{Ch} 2$ on dietary recommendations and gap analysis; CL: contributor to $\mathrm{Ch} 2$ on dietary gap analysis; EO: contributor together with PDS on $\mathrm{Ch} 3$, animal-sourced foods; MR: overall review and advisor; ET: contribution to Ch 2 , specifically sustainable diets; SV: contribution to $\mathrm{Ch} 3$, specifically ultra-processed foods. All authors reviewed and commented on previous versions of the manuscript; all authors read and approved the final manuscript.

Funding This article was funded by the International Fund for Agricultural Development (IFAD) and supported by the CGIAR Research Program on Agriculture for Nutrition and Health (A4NH).

\section{Declarations}

Conflict of interest The authors have no conflict of interest to declare that are relevant to the content of this article.

Open Access This article is licensed under a Creative Commons Attribution 4.0 International License, which permits use, sharing, adaptation, distribution and reproduction in any medium or format, as long as you give appropriate credit to the original author(s) and the source, provide a link to the Creative Commons licence, and indicate if changes were made. The images or other third party material in this article are included in the article's Creative Commons licence, unless indicated otherwise in a credit line to the material. If material is not included in the article's Creative Commons licence and your intended use is not permitted by statutory regulation or exceeds the permitted use, you will need to obtain permission directly from the copyright holder. To view a copy of this licence, visit http://creativecommons.org/licenses/by/4.0/.

\section{References}

Abegaz, G. A., Hassen, I. W., \& Minten, B. (2018). Consumption of animal-source foods in Ethiopia: Patterns, changes, and determinants. World Development, 106(November 27 2017), 1-10. Retrieved from http://www.worldreligiondatabase.org/wrd_home. asp\%0Ahttp://ebrary.ifpri.org/cdm/ref/collection/p15738coll2/id/ 131369\%0Ahttp://ebrary.ifpri.org/cdm/ref/collection/p15738coll2/ id/132252

Abril, E. P., \& Dempsey, P. R. (2019). Outcomes of healthy eating Ad campaigns: A systematic review. Progress in Cardiovascular Diseases, 62(1), 39-43. https://doi.org/10.1016/j.pcad.2018.12.008

Adams, J., \& White, M. (2015). Characterisation of UK diets according to degree of food processing and associations with socio-demographics and obesity: Cross-sectional analysis of UK National Diet and Nutrition Survey (2008-12). International Journal of Behavioral Nutrition and Physical Activity, 12, 160. https://doi. org/10.1186/s12966-015-0317-y

Adjibade, M., Julia, C., Allès, B., Touvier, M., Lemogne, C., Srour, B., et al. (2019). Prospective association between ultra-processed food consumption and incident depressive symptoms in the French NutriNet-Santé cohort. BMC Medicine, 17, 78. https:// doi.org/10.1186/s12916-019-1312-y
Allemandi, L., Castronuovo, L., Tiscornia, M. V., Ponce, M., \& Schoj, V. (2018). Food advertising on Argentinean television: Are ultraprocessed foods in the lead? Public Health Nutrition, 21(1), 238246. https://doi.org/10.1017/S1368980017001446

Anzman-Frasca, S., Mueller, M. P., Sliwa, S., Dolan, P. R., Harelick, L., Roberts, S. B., et al. (2015). Changes in children's meal orders following healthy menu modifications at a regional US restaurant chain. Obesity, 23(5), 1055-1062. https://doi.org/10.1002/oby.21061

Araya, S., Elberg, A., Noton, C., \& Schwartz, D. (2020). Identifying food labeling effects on consumer behavior. https://doi.org/10. 2139/ssrn.3195500

Ares, G., Machín, L., Girona, A., Curutchet, M. R., \& Giménez, A. (2017). Comparison of motives underlying food choice and barriers to healthy eating among low medium income consumers in Uruguay. Cadernos De Saúde Pública, 33(4), e00213315. https:// doi.org/10.1590/0102-311x00213315

Ariely, D. (2010). Predictably irrational: The hidden forces that shape our decisions. Harper Perennial.

Aunger, R., \& Curtis, V. (2013). The anatomy of motivation: An evolutionary-ecological approach. Biological Theory, 8, 49-63. https://doi.org/10.1007/s13752-013-0101-7

Ayuya, O. I., Ireri, D. M., Kithinji, J., Ndambi, A., Kilelu, C., Bebe, B. O., et al. (2020). Milk dispensing machines in Kenya's dairy industry: trends and scenario analysis. Wageningen. https://doi. org/10.18174/521451

Bai, Y., Naumova, E. N., \& Masters, W. A. (2020). Seasonality of diet costs reveals food system performance in East Africa. Science Advances. https://doi.org/10.1126/sciadv.abc2162

Bailey, R. L., West, K. P., Jr., \& Black, R. E. (2015). The epidemiology of global micronutrient deficiencies. Annals of Nutrition and Metabolism, 66(2), 22-33. https://doi.org/10.1159/ 000371618

Baker, P., \& Friel, S. (2014). Processed foods and the nutrition transition: Evidence from Asia. Obesity Reviews, 15(7), 564-577. https://doi.org/10.1111/obr.12174

Baker, P., \& Friel, S. (2016). Food systems transformations, ultraprocessed food markets and the nutrition transition in Asia. Globalization and Health, 12(1), 80. https://doi.org/10.1186/ s12992-016-0223-3

Baker, P., Machado, P., Santos, T., Sievert, K., Backholer, K., Hadjikakou, M., et al. (2020). Ultra-processed foods and the nutrition transition: Global, regional and national trends, food systems transformations and political economy drivers. Obesity Reviews. https://doi.org/10. 1111/obr.13126

Banwell, C., Dixon, J., Seubsman, S.-A., Pangsap, S., Kelly, M., \& Sleigh, A. (2012). Evolving food retail environments in Thailand and implications for the health and nutrition transition. Public Health Nutrition, 16(4), 608-615. https://doi.org/10.1017/S1368980012004223

Barnett, I., Scott, N., Batchelor, S., \& Haddad, L. (2016). Dial "N" for nutrition? A Landscape Analysis of What We Know about m-Nutrition, m-Agriculture and m-Development (Vol. 2016). Brighton. Retrieved from https://opendocs.ids.ac.uk/opendocs/ handle/20.500.12413/12642

Barnett, I., Gordon, J., Faith, B., Gilligan, D. O., Hidrobo, M., Palloni, G., et al. (2020). Using mobile-phone technology to change behaviour: Lessons from mNutrition. UNSCN Nutrition, 45, 25-32.

Batal, M., Johnson-Down, L., Moubarac, J.-C., Ing, A., Fediuk, K., Sadik, T., et al. (2018). Quantifying associations of the dietary share of ultra-processed foods with overall diet quality in First Nations peoples in the Canadian provinces of British Columbia, Alberta, Manitoba and Ontario. Public Health Nutrition, 21(1), 103-113. https://doi.org/10.1017/S1368980017001677

Behrens, P., Kiefte-de Jong, J. C., Bosker, T., Rodrigues, J. F. D., de Koning, A., \& Tukker, A. (2017). Evaluating the environmental impacts of dietary recommendations. Proceedings of the 
National Academy of Sciences, 114(51), 13412-13417. https:// doi.org/10.1073/pnas.1711889114

Béné, C., Oosterveer, P., Lamotte, L., Brouwer, I. D., de Haan, S., Prager, S. D., et al. (2019). When food systems meet sustainability-Current narratives and implications for actions. World Development, 113, 116-130. https://doi.org/10.1016/j.worlddev. 2018.08.011

Benedict, R. K., Craig, H. C., Torlesse, H., \& Stoltzfus, R. J. (2018). Effectiveness of programmes and interventions to support optimal breastfeeding among children 0-23 months, South Asia: A scoping review. Maternal \& Child Nutrition, 14(S4), e12697. https://doi.org/10.1111/mcn.12697

BEUC. (2020). One bite at a time: consumers and the transition to sustainable food - Analysis of a survey of European consumers on attitudes towards sustainable food. Brussels. Retrieved from https://euagenda.eu/publications/one-bite-at-a-time-consumersand-the-transition-to-sustainable-food-analysis-of-a-survey-ofeuropean-consumers-on-attitudes-towards-sustainable-food

Bielemann, R. M., Santos Motta, J. V., Minten, G. C., Horta, B. L., \& Gigante, D. P. (2015). Consumption of ultra-processed foods and their impact on the diet of young adults. Revista De Saúde Pública. https://doi.org/10.1590/S0034-8910.2015049005572

Bivoltsis, A., Cervigni, E., Trapp, G., Knuiman, M., Hooper, P., \& Ambrosini, G. L. (2018). Food environments and dietary intakes among adults: Does the type of spatial exposure measurement matter? A systematic review. International Journal of Health Geographics, 17(1), 19. https://doi.org/10.1186/ s12942-018-0139-7

Bivoltsis, A., Trapp, G., Knuiman, M., Hooper, P., \& Ambrosini, G. L. (2020). The influence of the local food environment on diet following residential relocation: Longitudinal results from RESIDential Environments (RESIDE). Public Health Nutrition, 23(12), 2132-2144. https://doi.org/10.1017/S1368980019005111

Blackstone, N. T., El-Abbadi, N. H., McCabe, M. S., Griffin, T. S., \& Nelson, M. E. (2018). Linking sustainability to the healthy eating patterns of the Dietary Guidelines for Americans: A modelling study. The Lancet Planetary Health, 2(8), e344-e352. https://doi. org/10.1016/S2542-5196(18)30167-0

Blanco-Rojo, R., Sandoval-Insausti, H., López-Garcia, E., Graciani, A., Ordovás, J. M., Banegas, J. R., et al. (2019). Consumption of ultra-processed foods and mortality: A national prospective cohort in Spain. Mayo Clinic Proceedings, 94(11), 2178-2188. https://doi.org/10.1016/j.mayocp.2019.03.035

Block, S. A., Kiess, L., Webb, P., Kosen, S., Moench-Pfanner, R., Bloem, M. W., \& Peter Timmer, C. (2004). Macro shocks and micro outcomes: Child nutrition during Indonesia's crisis. Economics \& Human Biology, 2(1), 21-44. https://doi.org/10.1016/j. ehb.2003.12.007

Borzekowski, D. L., \& Robinson, T. N. (2001). The 30-second effect: An experiment revealing the impact of television commercials on food preferences of preschoolers. Journal of the American Dietetic Association, 101(1), 42-46. https://doi.org/10.1016/ S0002-8223(01)00012-8

Boyland, E. J., Harrold, J. A., Kirkham, T. C., Corker, C., Cuddy, J., Evans, D., et al. (2011). Food commercials increase preference for energy-dense foods, particularly in children who watch more television. Pediatrics, 128(1), e93-e100. https://doi.org/10.1542/ peds.2010-1859

Boyland, E. J., Nolan, S., Kelly, B., Tudur-Smith, C., Jones, A., Halford, J. C. G., \& Robinson, E. (2016). Advertising as a cue to consume: A systematic review and meta-analysis of the effects of acute exposure to unhealthy food and nonalcoholic beverage advertising on intake in children and adults. American Journal of Clinical Nutrition, 103(2), 519-533. https://doi.org/10.3945/ajcn.115.120022

Brinkman, H.-J., de Pee, S., Sanogo, I., Subran, L., \& Bloem, M. W. (2010). High food prices and the global financial crisis have reduced access to nutritious food and worsened nutritional status and health. The Journal of Nutrition, 140(1), 153S-161S. https:// doi.org/10.3945/jn.109.110767

Brouwer, I. D., McDermott, J., \& Ruben, R. (2020). Food systems everywhere: Improving relevance in practice. Global Food Security, 26, 100398. https://doi.org/10.1016/j.gfs.2020.100398

Buijzen, M., \& Valkenburg, P. M. (2003). The effects of television advertising on materialism, parent-child conflict, and unhappiness: A review of research. Journal of Applied Developmental Psychology, 24(4), 437-456. https://doi.org/10.1016/S01933973(03)00072-8

Byker, C. J., Misyak, S., Shanks, J., \& Serrano, E. L. (2013). Do farmers' markets improve diet of participants using federal nutrition assistance programs? A literature review. Journal of Extension, 51(6). Retrieved from https://scholarworks.montana.edu/xmlui/ handle/1/9517

Cameron, A. J., Charlton, E., Ngan, W. W., \& Sacks, G. (2016). A systematic review of the effectiveness of supermarket-based interventions involving product, promotion, or place on the healthiness of consumer purchases. Current Nutrition Reports, 5, 129-138. https://doi.org/10.1007/s13668-016-0172-8

Canella, D. S., Levy, R. B., Martins, A. P. B., Claro, R. M., Moubarac, J.-C., Baraldi, L. G., et al. (2014). Ultra-processed food products and obesity in Brazilian households (2008-2009). PLOS ONE, 9(3), e92752. https://doi.org/10.1371/journal.pone.0092752

Canhada, S. L., Luft, V. C., Giatti, L., Duncan, B. B., Chor, D., Fonseca, M., de Maria, J. M., et al. (2020). Ultra-processed foods, incident overweight and obesity, and longitudinal changes in weight and waist circumference: the Brazilian Longitudinal Study of Adult Health (ELSA-Brasil). Public Health Nutrition, 23(6), 1076-1086. https://doi.org/10.1017/S1368980019002854

Cattafesta, M., Petarli, G. B., da Luz, T. C., Zandonade, E., de Paula Alves Bezerra, O. M., \& Salaroli, L. B. (2020). Dietary patterns of Brazilian farmers and their relation with sociodemographic, labor, and lifestyle conditions. Nutrition Journal, 19(1), 23. https://doi.org/10.1186/s12937-020-00542-y

Cecchini, M., \& Warin, L. (2016). Impact of food labelling systems on food choices and eating behaviours: A systematic review and meta-analysis of randomized studies. Obesity Reviews, 17(3), 201-210. https://doi.org/10.1111/obr.12364

Cediel, G., Reyes, M., Corvalán, C., Levy, R. B., Uauy, R., \& Monteiro, C. A. (2020). Ultra-processed foods drive to unhealthy diets: Evidence from Chile. Public Health Nutrition. https://doi.org/ 10.1017/S1368980019004737

Chai, B. C., van der Voort, J. R., Grofelnik, K., Eliasdottir, H. G., Klöss, I., \& Perez-Cueto, F. J. A. (2019). Which diet has the least environmental impact on our planet? A systematic review of vegan, vegetarian and omnivorous diets. Sustainability, 11(15), 4110. https://doi.org/10.3390/su11154110

Chambers, S. A., Freeman, R., Anderson, A. S., \& MacGillivray, S. (2015). Reducing the volume, exposure and negative impacts of advertising for foods high in fat, sugar and salt to children: A systematic review of the evidence from statutory and self-regulatory actions and educational measures. Preventive Medicine, 75, 32-43. https://doi.org/10.1016/j.ypmed.2015.02.011

Chau, M. M., Burgermaster, M., \& Mamykina, L. (2018). The use of social media in nutrition interventions for adolescents and young adults-A systematic review. International Journal of Medical Informatics, 120, 77-91. https://doi.org/10.1016/j.ijmedinf.2018. 10.001

Chen, Y.-C., Huang, Y.-C., Lo, Y.-T.C., Wu, H.-J., Wahlqvist, M. L., \& Lee, M.-S. (2018). Secular trend towards ultra-processed food consumption and expenditure compromises dietary quality among Taiwanese adolescents. Food \& Nutrition Research. https://doi.org/10.29219/fnr.v62.1565 
Cisneros, P. M. C., \& Silva, C. L. H. (2017). Temporal discounting and health behavior: A review. MOJ Public Health. https://doi.org/ 10.15406/mojph.2017.06.00189

Clark, M. A., Springmann, M., Hill, J., \& Tilman, D. (2019). Multiple health and environmental impacts of foods. Proceedings of the National Academy of Sciences, 116(46), 23357-23362. https:// doi.org/10.1073/pnas.1906908116

Colchero, M. A., Rivera-Dommarco, J., Popkin, B. M., \& Ng, S. W. (2017). In Mexico, evidence of sustained consumer response two years after implementing a sugar-sweetened beverage tax. Health Affairs, 36, 564-571. https://doi.org/10.1377/hlthaff.2016.1231

Colchero, M. A., Guerrero-López, C. M., Molina, M., \& Unar-Munguía, M. (2019). Affordability of food and beverages in Mexico between 1994 and 2016. Nutrients, 11(1), 78. https://doi.org/10.3390/nu11010078

Cornwell, B., Villamor, E., Mora-Plazas, M., Marin, C., Monteiro, C. A., \& Baylin, A. (2018). Processed and ultra-processed foods are associated with lower-quality nutrient profiles in children from Colombia. Public Health Nutrition, 21(1), 142-147. https://doi. org/10.1017/S1368980017000891

D'Alimonte, M. R., Deshmukh, D., Jayaraman, A., Chanani, S., \& Humphries, D. L. (2016). Using positive deviance to understand the uptake of optimal infant and young child feeding practices by mothers in an urban slum of Mumbai. Maternal and Child Health Journal, 20(6), 1133-1142. https://doi.org/10.1007/ s10995-015-1899-3

da Costa Louzada, M. L., da Martins, A. P. B., Canella, D. S., Baraldi, L. G., Levy, R. B., Claro, R. M., et al. (2015). Impact of ultraprocessed foods on micronutrient content in the Brazilian diet. Revista De Saude Publica. https://doi.org/10.1590/S0034-8910. 2015049006211

da Costa Louzada, M. L., Ricardo, C. Z., Steele, E. M., Levy, R. B., Cannon, G., \& Monteiro, C. A. (2018). The share of ultra-processed foods determines the overall nutritional quality of diets in Brazil. Public Health Nutrition, 21(1), 94-102. https://doi.org/10.1017/S1368980017001434

Dake, F. A. A., Thompson, A. L., Ng, S. W., Agyei-Mensah, S., \& Codjoe, S. N. A. (2016). The local food environment and body mass index among the urban poor in Accra, Ghana. Journal of Urban Health, 93(3), 438-455. https://doi.org/10.1007/s11524-016-0044-y

Darmon, N., \& Drewnowski, A. (2015). Contribution of food prices and diet cost to socioeconomic disparities in diet quality and health: A systematic review and analysis. Nutrition Reviews, 73(10), 643-660. https://doi.org/10.1093/nutrit/nuv027

Dasi, T., Selvaraj, K., Pullakhandam, R., \& Kulkarni, B. (2019). Animal source foods for the alleviation of double burden of malnutrition in countries undergoing nutrition transition. Animal Frontiers, 9(4), 32-38. https://doi.org/10.1093/af/vfz031

de Groot, R., Palermo, T., Handa, S., Ragno, L. P., \& Peterman, A. (2017). Cash transfers and child nutrition: Pathways and impacts. Development Policy Review, 35(5), 621-643. https://doi.org/10. 1111/dpr.12255

de Mendonça, R. D., Lopes, A. C. S., Pimenta, A. M., Gea, A., Martinez-Gonzalez, M. A., \& Bes-Rastrollo, M. (2017). Ultra-processed food consumption and the incidence of hypertension in a mediterranean cohort: The Seguimiento Universidad de Navarra Project. American Journal of Hypertension, 30(4), 358-366. https://doi.org/10.1093/ajh/hpw137

de Mendonça, R. D., Pimenta, A. M., Gea, A., de la Fuente-Arrillaga, C., Martinez-Gonzalez, M. A., Lopes, A. C. S., \& Bes-Rastrollo, M. (2016). Ultraprocessed food consumption and risk of overweight and obesity: the University of Navarra Follow-Up (SUN) cohort study. The American Journal of Clinical Nutrition, 104(5), 1433-1440. https://doi.org/10.3945/ajcn.116.135004

Development Initiatives. (2018). 2018 Global Nutrition Report. Global Nutrition Report. Development Initiatives.

Development Initiatives. (2020). 2020 global nutrition report: Action on equity to end malnutrition. Development Initiatives.
Dhar, T., \& Baylis, K. (2011). Fast-food consumption and the ban on advertising targeting children: The Quebec experience. Journal of Marketing Research, 48(5), 799-813. https://doi.org/10.1509/ jmkr.48.5.799

dos Passos, C. M., Maia, E. G., Levy, R. B., Martins, A. P. B., \& Claro, R. M. (2020). Association between the price of ultra-processed foods and obesity in Brazil. Nutrition, Metabolism and Cardiovascular Diseases, 30(4), 589-598. https://doi.org/10.1016/j. numecd.2019.12.011

Downs, S. M., Ahmed, S., Fanzo, J., \& Herforth, A. (2020). Food environment typology: Advancing an expanded definition, framework, and methodological approach for improved characterization of wild, cultivated, and built food environments toward sustainable diets. Foods, 9(4), 532. https://doi.org/10.3390/foods 9040532

Downs, S., \& Fanzo, J. (2016). Chapter 1.3: Managing value chains for improved nutrition. Good nutrition: Perspectives for the 21st century (pp. 45-59). Karger Publishers. https://doi.org/10.1159/ 000452374

Draper, C. E., Grobler, L., Micklesfield, L. K., \& Norris, S. A. (2015). Impact of social norms and social support on diet, physical activity and sedentary behaviour of adolescents: A scoping review. Child: Care, Health and Development, 41(5), 654-667. https:// doi.org/10.1111/cch.12241

Dunning, R., Bloom, J. D., \& Creamer, N. (2015). The local food movement, public-private partnerships, and food system resiliency. Journal of Environmental Studies and Sciences, 5, 661670. https://doi.org/10.1007/s13412-015-0295-z

Fagerberg, P., Langlet, B., Oravsky, A., Sandborg, J., Löf, M., \& Ioakimidis, I. (2019). Ultra-processed food advertisements dominate the food advertising landscape in two Stockholm areas with low vs high socioeconomic status. Is it time for regulatory action? BMC Public Health, 19, 1717. https://doi.org/10.1186/ s12889-019-8090-5

Fanzo, J., Haddad, L., McLaren, R., Marshall, Q., Davis, C., Herforth, A., et al. (2020). The food systems dashboard is a new tool to inform better food policy. Nature Food, 1, 243-246. https://doi. org/10.1038/s43016-020-0077-y

FAO \& WHO. (2019). Sustainable healthy diets-Guiding principles. FAO \& WHO. https://doi.org/10.4060/CA6640EN

FAO, Ifad, UNICEF, WFP, \& WHO. (2020). The state of food security and nutrition in the world 2020. Transforming food systems for affordable healthy diets. FAO, Ifad, UNICEF, WFP, \& WHO. https://doi.org/10.4060/ca9692en

Farley, S. M., Sacks, R., Dannefer, R., Johns, M., Leggat, M., Lim, S., et al. (2015). Evaluation of the New York City Green Carts program. AIMS Public Health, 2(4), 906-918. https://doi.org/10. 3934/publichealth.2015.4.906

Fernández, C. I. (2020). Nutrition transition and health outcomes among indigenous populations of Chile. Current Developments in Nutrition, 4(5), nzaa070. https://doi.org/10.1093/cdn/nzaa070

Filgueiras, A. R., Pires de Almeida, V. B., Koch Nogueira, P. C., Alvares Domene, S. M., Eduardo da Silva, C., Sesso, R., \& Sawaya, A. L. (2019). Exploring the consumption of ultra-processed foods and its association with food addiction in overweight children. Appetite, 135, 137-145. https://doi.org/10.1016/j.appet.2018.11.005

Fiolet, T., Srour, B., Sellem, L., Kesse-Guyot, E., Allès, B., Méjean, C., et al. (2018). Consumption of ultra-processed foods and cancer risk: Results from NutriNet-Santé prospective cohort. $B M J, 360$, k322. https://doi.org/10.1136/bmj.k322

Fleming-Milici, F., \& Harris, J. L. (2020). Adolescents' engagement with unhealthy food and beverage brands on social media. Appetite, 146, 104501. https://doi.org/10.1016/j.appet.2019.104501

Ford, P. B., \& Dzewaltowski, D. A. (2008). Disparities in obesity prevalence due to variation in the retail food environment: Three 
testable hypotheses. Nutrition Reviews, 66(4), 216-228. https:// doi.org/10.1111/j.1753-4887.2008.00026.x

Fowles, E. R., Hendricks, J. A., \& Walker, L. O. (2005). Identifying healthy eating strategies in low-income pregnant women: Applying a positive deviance model. Health Care for Women International, 26(9), 807-820. https://doi.org/10.1080/07399 330500230953

Frewer, L. J., Risvik, E., \& Schifferstein, H. (2001). Food, people and society: A European perspective of consumers' food choices. Springer.

Gama, A. P., Adhikari, K., \& Hoisington, D. A. (2018). Factors influencing food choices of Malawian consumers: A food choice questionnaire approach. Journal of Sensory Studies, 33(5), e12442. https://doi.org/10.1111/joss.12442

Gamboa-Gamboa, T., Blanco-Metzler, A., Vandevijvere, S., RamirezZea, M., \& Kroker-Lobos, M. F. (2019). Nutritional content according to the presence of front of package marketing strategies: The case of ultra-processed snack food products purchased in Costa Rica. Nutrients, 11(11), 2738. https://doi.org/10.3390/ nu11112738

GBD 2017 Diet Collaborators. (2019). Health effects of dietary risks in 195 countries, 1990-2017: A systematic analysis for the Global Burden of Disease Study 2017. The Lancet, 393(10184), 19581972. https://doi.org/10.1016/S0140-6736(19)30041-8

Gissing, S. C., Pradeilles, R., Osei-Kwasi, H. A., Cohen, E., \& Holdsworth, M. (2017). Drivers of dietary behaviours in women living in urban Africa: A systematic mapping review. Public Health Nutrition, 20(12), 2104-2113. https://doi.org/10.1017/S1368980017000970

Glanz, K., Bader, M. D. M., \& Iyer, S. (2012). Retail grocery store marketing strategies and obesity. American Journal of Preventive Medicine, 42(5), 503-512. https://doi.org/10.1016/j.amepre. 2012.01.013

Global Food Research Program. (2020). Sugary drink taxes around the world. Global Food Research Program.

GLOPAN. (2020). Future food systems: For people, our planet, and prosperity. Global Panel on Agriculture and Food Systems for Nutrition.

Gómez-Donoso, C., Sánchez-Villegas, A., Martínez-González, M. A., Gea, A., de Deus Mendonça, R., Lahortiga-Ramos, F., \& BesRastrollo, M. (2020). Ultra-processed food consumption and the incidence of depression in a Mediterranean cohort: the SUN Project. European Journal of Nutrition, 59, 1093-1103. https:// doi.org/10.1007/s00394-019-01970-1

Grace, D., Domoniguez-Sala, P., Alonso, S., Muunda, E., Ngwili, N., Omar, A., et al. (2018). The influence of livestock- derived foods on nutrition during the first 1, 000 days of life Agriculture for.

Graziose, M. M., Downs, S. M., O’Brien, Q., \& Fanzo, J. (2018). Systematic review of the design, implementation and effectiveness of mass media and nutrition education interventions for infant and young child feeding. Public Health Nutrition, 21(2), 273-287. https://doi.org/10.1017/S1368980017002786

Green, R., Cornelsen, L., Dangour, A. D., Turner, R., Shankar, B., Mazzocchi, M., \& Smith, R. D. (2013). The effect of rising food prices on food consumption: Systematic review with metaregression. BMJ, 346, f3703. https://doi.org/10.1136/bmj.f3703

Grummon, A. H., Lockwood, B. B., Taubinsky, D., \& Allcott, H. (2019). Designing better sugary drink taxes. Science, 365(6457), 989-990. https://doi.org/10.1126/science.aav5199

GSMA. (2019). Closing the coverage gap: How innovation can drive rural connectivity. GSMA.

Gupta, S., Hawk, T., Aggarwal, A., \& Drewnowski, A. (2019). Characterizing ultra-processed foods by energy density, nutrient density, and cost. Frontiers in Nutrition, 6, 70. https://doi.org/10.3389/ fnut. 2019.00070

Gurmu, A. B., Nykänen, E.-P.A., Alemayehu, F. R., Robertson, A., \& Parlesak, A. (2019). Cost-minimized nutritionally adequate food baskets as basis for culturally adapted dietary guidelines for Ethiopians. Nutrients, 11(9), 2159. https://doi.org/10.3390/ nu11092159

Gustafson, A., Hankins, S., \& Jilcott, S. (2012). Measures of the consumer food store environment: A systematic review of the evidence 2000-2011. Journal of Community Health, 37, 897-911. https://doi.org/10.1007/s10900-011-9524-x

Gwozdz, W., Reisch, L., Eiben, G., Hunsberger, M., Konstabel, K., Kovacs, E., et al. (2020). The effect of smileys as motivational incentives on children's fruit and vegetable choice, consumption and waste: A field experiment in schools in five European countries. Food Policy. https://doi.org/10.1016/j.foodpol.2020.101852

Hall, K. D., Ayuketah, A., Brychta, R., Cai, H., Cassimatis, T., Chen, K. Y., et al. (2019). Ultra-processed diets cause excess calorie intake and weight gain: An inpatient randomized controlled trial of ad libitum food intake. Cell Metabolism, 30(1), 67-77. e3. https://doi.org/10.1016/j.cmet.2019.05.008

Hanna, R., \& Olken, B. A. (2018). Universal basic incomes versus targeted transfers: Anti-poverty programs in developing countries. Journal of Economic Perspectives, 32(4), 201-226. https://doi. org/10.1257/jep.32.4.201

Hawkes, C., Ruel, M. T., Salm, L., Sinclair, B., \& Branca, F. (2020). Double-duty actions: Seizing programme and policy opportunities to address malnutrition in all its forms. The Lancet, 395(10218), 142-155. https://doi.org/10.1016/S0140-6736(19)32506-1

Headey, D., Hirvonen, K., \& Hoddinott, J. (2017). Animal sourced foods and child stunting. https://ageconsearch.umn.edu/record/ 265863/files/Headeyetal.ASFsnutrition_DPrevised.pdf

Headey, D. D., \& Alderman, H. H. (2019). The relative caloric prices of healthy and unhealthy foods differ systematically across income levels and continents. The Journal of Nutrition, 149(11), 2020-2033. https://doi.org/10.1093/jn/nxz158

Herforth, A., Bai, Y., Venkat, A., Mahrt, K., Ebel, A., \& Masters, W. A. (2020). Cost and affordability of healthy diets across countries. Background paper for the State of Food Security and Nutrition in the World 2020. Rome. Retrieved from https://sites.tufts.edu/ candasa/files/2020/08/HerforthEtAl_BackgroundPaperForSOFI_ FAO-ESA-TechnicalSeries_14Aug2020.pdf

Herforth, A., \& Ahmed, S. (2015). The food environment, its effects on dietary consumption, and potential for measurement within agriculture-nutrition interventions. Food Security, 7, 505-520. https://doi.org/10.1007/s12571-015-0455-8

Herforth, A., Arimond, M., Álvarez-Sánchez, C., Coates, J., Christianson, K., \& Muehlhoff, E. (2019). A global review of food-based dietary guidelines. Advances in Nutrition, 10(4), 590-605. https://doi.org/ 10.1093/advances/nmy130

Hilmers, A., Hilmers, D. C., \& Dave, J. (2012). Neighborhood disparities in access to healthy foods and their effects on environmental justice. American Journal of Public Health, 102(9), 1644-1654. https://doi.org/10.2105/AJPH.2012.300865

Hirvonen, K., Bai, Y., Headey, D., \& Masters, W. A. (2020). Affordability of the EAT-Lancet reference diet: A global analysis. The Lancet Global Health, 8(1), e59-e66. https://doi.org/10.1016/ S2214-109X(19)30447-4

HLPE. (2017). Nutrition and food systems. A report by the high level panel of experts on food security and nutrition of the Committee on World Food Security. HLPE.

Hsu, M. S. H., Rouf, A., \& Allman-Farinelli, M. (2018). Effectiveness and behavioral mechanisms of social media interventions for positive nutrition behaviors in adolescents: A systematic review. Journal of Adolescent Health, 63(5), 531-545. https://doi.org/10. 1016/j.jadohealth.2018.06.009

Imamura, F., Micha, R., Khatibzadeh, S., Fahimi, S., Shi, P., Powles, J., \& Mozaffarian, D. (2015). Dietary quality among men and women in 187 countries in 1990 and 2010: A systematic 
assessment. The Lancet Global Health, 3(3), e132-e142. https:// doi.org/10.1016/S2214-109X(14)70381-X

Jackson, P., \& Viehoff, V. (2016). Reframing convenience food. Appetite, 98, 1-11. https://doi.org/10.1016/j.appet.2015.11.032

Jensen, J. D., \& Smed, S. (2018). State-of-the-art for food taxes to promote public health. Proceedings of the Nutrition Society, 77(2), 100-105. https://doi.org/10.1017/S0029665117004050

Jensen, M. L., Carpentier, F. D., Adair, L., Corvalán, C., Popkin, B. M., \& Taillie, L. S. (2020). Examining Chile's unique food marketing policy: TV advertising and dietary intake in preschool children, a pre- and post- policy study. Pediatric Obesity. https://doi.org/10. 1111/ijpo.12735

Johns, D. J., Langley, T. E., \& Lewis, S. (2017). Use of social media for the delivery of health promotion on smoking, nutrition, and physical activity: A systematic review. The Lancet, 390, S49. https://doi.org/10.1016/S0140-6736(17)32984-7

Kahneman, D. (2011). Thinking, fast and slow. Farrar, Straus and Giroux.

Kassebaum, N. J., Jasrasaria, R., Naghavi, M., Wulf, S. K., Johns, N., Lozano, R., et al. (2014). A systematic analysis of global anemia burden from 1990 to 2010. Blood, 123(5), 615-624. https://doi. org/10.1182/blood-2013-06-508325

Kearney, J. (2010). Food consumption trends and drivers. Philosophical Transactions of the Royal Society B: Biological Sciences, 365(1554), 2793-2807. https://doi.org/10.1098/rstb.2010.0149

Keats, S., Mallipu, A., Menon, R., Poonawala, A., Sutrisna, A., \& Tumilowicz, A. (2019). The Baduta programme in East Java, Indonesia. What works in communicating for better nutrition? Geneva, Switzerland. https://doi.org/10.36072/wp.1

Kelly, B., King, L., Chapman, K., Boyland, E., Bauman, A. E., \& Baur, L. A. (2015). A hierarchy of unhealthy food promotion effects: Identifying methodological approaches and knowledge gaps. American Journal of Public Health, 105(4), e86-e95. https:// doi.org/10.2105/AJPH.2014.302476

Kelly, B., Vandevijvere, S., Ng, S., Adams, J., Allemandi, L., BahenaEspina, L., et al. (2019). Global benchmarking of children's exposure to television advertising of unhealthy foods and beverages across 22 countries. Obesity Reviews, 20(S2), 116-128. https://doi.org/10.1111/obr.12840

Khoury, C. K., Bjorkman, A. D., Dempewolf, H., Ramirez-Villegas, J., Guarino, L., Jarvis, A., et al. (2014). Increasing homogeneity in global food supplies and the implications for food security. Proceedings of the National Academy of Sciences, 111(11), 4001-4006. https://doi.org/10.1073/pnas.1313490111

Kim, B. F., Santo, R. E., Scatterday, A. P., Fry, J. P., Synk, C. M., Cebron, S. R., et al. (2020a). Country-specific dietary shifts to mitigate climate and water crises. Global Environmental Change, 62, 101926. https://doi.org/10.1016/j.gloenvcha.2019.05.010

Kim, S. S., Nguyen, P. H., Tran, L. M., Alayon, S., Menon, P., \& Frongillo, E. A. (2020b). Different combinations of behavior change interventions and frequencies of interpersonal contacts are associated with infant and young child feeding practices in Bangladesh, Ethiopia, and Vietnam. Current Developments in Nutrition, 4(2), nzz140. https://doi.org/10.1093/cdn/nzz140

Koen, N., Wentzel-Viljoen, E., \& Blaauw, R. (2018). Price rather than nutrition information the main influencer of consumer food purchasing behaviour in South Africa: A qualitative study. International Journal of Consumer Studies, 42(4), 409-418. https://doi. org/10.1111/ijcs. 12434

Kotler, P., \& Armstrong, G. (2018). Principles of marketing (17th ed.). Pearson.

Kyere, P., Lennert Veerman, J., Lee, P., \& Stewart, D. (2020). Effectiveness of school-based nutrition interventions in sub-Saharan Africa: A systematic review. Public Health Nutrition, 23(14), 2626-2636. https://doi.org/10.1017/S1368980020000506

Lachat, C., Otchere, S., Roberfroid, D., Abdulai, A., Seret, F. M. A., Milesevic, J., et al. (2013). Diet and physical activity for the prevention of noncommunicable diseases in low- and middleincome countries: A systematic policy review. PLoS Medicine. https://doi.org/10.1371/journal.pmed.1001465

Lamstein, S., Stillman, T., Koniz-Booher, P., Aakesson, A., Collaiezzi, B., Williams, T., et al. (2014). Evidence of effective approaches to social and behavior change communication for preventing and reducing stunting and anemia: Report from a systematic literature review. Arlington, VA. Retrieved from https://www. spring-nutrition.org/sites/default/files/publications/series/spring_ sbcc_lit_review.pdf

Latino, L. R., Pica-ciamarra, U., \& Wisser, D. (2020). Africa: The livestock revolution urbanizes. Global Food Security, 26, 100399. https://doi.org/10.1016/j.gfs.2020.100399

Lecoutere, E., van den Berg, M., \& de Brauw, A. (2021). Effective food systems innovations. IFPRI Discussion Paper, (May).

Leffa, P. S., Hoffman, D. J., Rauber, F., Sangalli, C. N., Valmórbida, J. L., \& Vitolo, M. R. (2020). Longitudinal associations between ultra-processed foods and blood lipids in childhood. British Journal of Nutrition, 124(3), 341-348. https://doi.org/10.1017/S0007114520001233

Lion, R., Arulogun, O., Titiloye, M., Shaver, D., Jain, A., Godwin, B., et al. (2018). The effect of the "Follow in my Green Food Steps" programme on cooking behaviours for improved iron intake: A quasi-experimental randomized community study. International Journal of Behavioral Nutrition and Physical Activity, 15(1), 1-14. https://doi.org/10.1186/s12966-018-0710-4

Logue, A. (1998). Evolutionary theory and the psychology of eating. Baruch College, City University of New York.

Long, M. W., Tobias, D. K., Cradock, A. L., Batchelder, H., \& Gortmaker, S. L. (2015). Systematic review and meta-analysis of the impact of restaurant menu calorie labeling. American Journal of Public Health, 105, e11-e24. https://doi.org/10.2105/AJPH.2015.302570

Lovasi, G. S., Hutson, M. A., Guerra, M., \& Neckerman, K. M. (2009). Built environments and obesity in disadvantaged populations. Epidemiologic Reviews, 31, 7-20. https://doi.org/10.1093/epirev/ mxp005

Lustig, R. H. (2020). Ultraprocessed food: Addictive, toxic, and ready for regulation. Nutrients, 12(11), 3401.

Mackay, S., Vandevijvere, S., Xie, P., Lee, A., \& Swinburn, B. (2017). Paying for convenience: Comparing the cost of takeaway meals with their healthier home-cooked counterparts in New Zealand. Public Health Nutrition, 20(13), 2269-2276. https://doi.org/10. 1017/S1368980017000805

Maguire, E. R., Burgoine, T., Penney, T. L., Forouhi, N. G., \& Monsivais, P. (2017). Does exposure to the food environment differ by socioeconomic position? Comparing area-based and person-centred metrics in the Fenland Study, UK. International Journal of Health Geographics, 16(1), 33. https://doi.org/10.1186/s12942-017-0106-8

Mallarino, C., Gómez, L. F., González-Zapata, L., Cadena, Y., \& Parra, D. C. (2013). Advertising of ultra-processed foods and beverages: Children as a vulnerable population. Revista De Saúde Pública, 47(5), 1006-1010. https://doi.org/10.1590/S0034-8910. 2013047004319

Mancini, M. C. (2019). Public and private food standards. In L. Dries, W. Heijman, R. Jongeneel, K. Purnhagen, \& J. Wesseler (Eds.), EU bioeconomy economics and policies (Vol. II, pp. 47-61). Palgrave Macmillan. https://doi.org/10.1007/978-3-030-28642-2_4

Mandle, J., Tugendhaft, A., Michalow, J., \& Hofman, K. (2015). Nutrition labelling: A review of research on consumer and industry response in the global South. Global Health Action, 8, 25912. https://doi.org/10.3402/gha.v8.25912

Marrón-Ponce, J. A., Sánchez-Pimienta, T. G., da Costa Louzada, M. L., \& Batis, C. (2018). Energy contribution of NOVA food groups and sociodemographic determinants of ultra-processed food consumption in the Mexican population. Public Health Nutrition, 21(1), 87-93. https://doi.org/10.1017/S1368980017002129 
Martínez Steele, E., Popkin, B. M., Swinburn, B., \& Monteiro, C. A. (2017). The share of ultra-processed foods and the overall nutritional quality of diets in the US: Evidence from a nationally representative cross-sectional study. Population Health Metrics, 15, 6. https://doi.org/10.1186/s12963-017-0119-3

Martins, A. P. B., Levy, R. B., Claro, R. M., Moubarac, J. C., \& Monteiro, C. A. (2013). Increased contribution of ultra-processed food products in the Brazilian diet (1987-2009). Revista De Saude Publica, 47(4), 656-665. https://doi.org/10.1590/S00348910.2013047004968

Masset, E., \& Gelli, A. (2013). Improving community development by linking agriculture. Nutrition and education. Design of a randomised field experiment of "home grown" school feeding in Mali. Trials, 14(55), 1745-6215.

Melnyk, V., van Herpen, E., Jak, S., \& van Trijp, H. C. M. (2019). The mechanisms of social norms' influence on consumer decision making. Zeitschrift Für Psychologie, 227(1), 4-17. https://doi. org/10.1027/2151-2604/a000352

Mendoza, A., Pérez, A. E., Aggarwal, A., \& Drewnowski, A. (2017). Energy density of foods and diets in Mexico and their monetary cost by socioeconomic strata: Analyses of ENSANUT data 2012. Journal of Epidemiology and Community Health, 71(7), 713721. https://doi.org/10.1136/jech-2016-207781

Menon, P., Nguyen, P. H., Saha, K. K., Khaled, A., Kennedy, A., Tran, L. M., et al. (2016). Impacts on breastfeeding practices of at-scale strategies that combine intensive interpersonal counseling, mass media, and community mobilization: Results of cluster-randomized program evaluations in Bangladesh and Viet Nam. PLOS Medicine, 13(10), e1002159. https://doi.org/10.1371/journal.pmed.1002159

Micha, R., Wallace, S. K., \& Mozaffarian, D. (2010). Red and processed meat consumption and risk of incident coronary heart disease, stroke, and diabetes mellitus. Circulation, 121(21), 2271-2283. https://doi.org/10.1161/CIRCULATIONAHA.109. 924977

Montanari, M. (2006). Food is culture. Columbia University Press.

Monteiro, C. A., Cannon, G., Levy, R. B., Moubarac, J.-C., Louzada, M. L. C., Rauber, F., et al. (2019). Ultra-processed foods: What they are and how to identify them. Public Health Nutrition, 22(5), 936-941. https://doi.org/10.1017/S1368980018003762

Monteiro, C. A., Cannon, G., Moubarac, J.-C., Levy, R. B., Louzada, M. L. C., \& Jaime, P. C. (2017). The UN Decade of Nutrition, the NOVA food classification and the trouble with ultra-processing. Public Health Nutrition, 21(1), 5-17. https://doi.org/10.1017/ S1368980017000234

Monteiro, C. A., Moubarac, J.-C., Levy, R. B., Canella, D. S., da Costa Louzada, M. L., \& Cannon, G. (2018). Household availability of ultra-processed foods and obesity in nineteen European countries. Public Health Nutrition, 21(1), 18-26. https://doi.org/10. 1017/S1368980017001379

Morris, S. S., Cogill, B., \& Uauy, R. (2008). Effective international action against undernutrition: Why has it proven so difficult and what can be done to accelerate progress? The Lancet. https://doi. org/10.1016/S0140-6736(07)61695-X

Moubarac, J.-C., Martins, A. P. B., Claro, R. M., Levy, R. B., Cannon, G., \& Monteiro, C. A. (2013). Consumption of ultra-processed foods and likely impact on human health. Evidence from Canada. Public Health Nutrition, 16, 2240-2248. https://doi.org/10.1017/ S1368980012005009

Moubarac, J.-C., Batal, M., Louzada, M. L., Martinez Steele, E., \& Monteiro, C. A. (2017). Consumption of ultra-processed foods predicts diet quality in Canada. Appetite, 108, 512-520. https:// doi.org/10.1016/j.appet.2016.11.006

Mozaffarian, D. (2016). Dietary and policy priorities for cardiovascular disease, diabetes, and obesity: A comprehensive review. Circulation, 133(2), 187-225. https://doi.org/10.1161/CIRCULATIONAHA.115. 018585
MQSUN+. (2018). Where business and nutrition meet review of approaches and evidence on private sector engagement in nutrition. MQSUN+.

Müller, A. M., Alley, S., Schoeppe, S., \& Vandelanotte, C. (2016). The effectiveness of e- $\&$ mHealth interventions to promote physical activity and healthy diets in developing countries: A systematic review. International Journal of Behavioral Nutrition and Physical Activity, 13, 109. https://doi.org/10.1186/s12966-016-0434-2

Murphy, S., \& Allen, L. H. (2003). Animal source foods to improve micronutrient nutrition and human function in developing countries: Nutrition importance of animal source foods. Journal of Nutrition, 133, 3875-3878.

Neri, D., Martinez-Steele, E., Monteiro, C. A., \& Levy, R. B. (2019). Consumption of ultra-processed foods and its association with added sugar content in the diets of US children, NHANES 20092014. Pediatric Obesity, 14, e12563. https://doi.org/10.1111/ijpo. 12563

Nguyen, T., de Brauw, A., van den Berg, M., \& Phuong Ha, D. T. (2020). Testing methods to increase consumption of healthy foods: Evidence from a school-based field experiment in Viet Nam (No. 1939). International Food Policy Research Institute (IFPRI). https://doi.org/10.2499/p15738coll2.133777

Nordhagen, S., Beal, T., \& Haddad, L. (2020). The role of animal-source foods in healthy, sustainable, and equitable food systems (Vol. 5). Global Alliance for Improved Nutrition (GAIN).

Norman, J., Kelly, B., McMahon, A.-T., Boyland, E., Baur, L. A., Chapman, K., et al. (2018). Sustained impact of energy-dense TV and online food advertising on children's dietary intake: A within-subject, randomised, crossover, counter-balanced trial. International Journal of Behavioral Nutrition and Physical Activity, 15(1), 37. https://doi.org/10.1186/s12966-018-0672-6

Nykänen, E.-P.A., Dunning, H. E., Aryeetey, R. N. O., Robertson, A., \& Parlesak, A. (2018). Nutritionally optimized, culturally acceptable, cost-minimized diets for low income ghanaian families using linear programming. Nutrients, 10(4), 461. https://doi.org/10.3390/ nu10040461

Olsho, L. E. W., Klerman, J. A., Wilde, P. E., \& Bartlett, S. (2016). Financial incentives increase fruit and vegetable intake among Supplemental Nutrition Assistance Program participants: A randomized controlled trial of the USDA Healthy Incentives Pilot. The American Journal of Clinical Nutrition, 104(2), 423-435. https:// doi.org/10.3945/ajen.115.129320

Osei-Kwasi, H., Mohindra, A., Booth, A., Laar, A., Wanjohi, M., Graham, F., et al. (2020). Factors influencing dietary behaviours in urban food environments in Africa: A systematic mapping review. Public Health Nutrition. https://doi.org/10.1017/S1368980019005305

Pagliai, G., Dinu, M., Madarena, M. P., Bonaccio, M., Iacoviello, L., \& Sofi, F. (2020). Consumption of ultra-processed foods and health status: A systematic review and meta-analysis. British Journal of Nutrition. https://doi.org/10.1017/S0007114520002688

PAHO. (2015). Ultra-processed food and drink products in Latin America: Trends, impact on obesity, policy implications. PAHO.

Pan, A., Sun, Q., Bernstein, A. M., Schulze, M. B., Manson, J. E., Willett, W. C., \& Hu, F. B. (2011). Red meat consumption and risk of type 2 diabetes: 3 cohorts of US adults and an updated metaanalysis. The American Journal of Clinical Nutrition, 94(4), 10881096. https://doi.org/10.3945/ajcn.111.018978

Pederson, C., Remans, R., Zornetzer, H., De Hemptinne, M., BruleChampagne, E., Jensen, S., et al. (2020). Game-changing innovations for healthy diets on a healthy planet: Insights from a Delphi Study. Geneva, Switzerland. https://doi.org/10.36072/wp.15

Pelto, G. H., \& Armar-Klemesu, M. (2011). Balancing nurturance, cost and time: Complementary feeding in Accra, Ghana. Maternal \& Child Nutrition, 7(s3), 66-81. https://doi.org/10.1111/j.17408709.2011.00351.x 
Pineda, E., Bascunan, J., \& Sassi, F. (2021). Improving the school food environment for the prevention of childhood obesity: What works and what doesn't. Obesity Reviews, 22(2), 1-32. https://doi.org/ 10.1111/obr.13176

Pinho, M. G. M., Mackenbach, J. D., den Braver, N. R., Beulens, J. J. W., Brug, J., \& Lakerveld, J. (2020). Recent changes in the Dutch foodscape: Socioeconomic and urban-rural differences. International Journal of Behavioral Nutrition and Physical Activity, 17(1), 43. https://doi.org/10.1186/s12966-020-00944-5

Pitt, E., Gallegos, D., Comans, T., Cameron, C., \& Thornton, L. (2017). Exploring the influence of local food environments on food behaviours: A systematic review of qualitative literature. Public Health Nutrition, 20(13), 2393-2405. https://doi.org/10.1017/ S1368980017001069

Pondor, I., Gan, W. Y., \& Appannah, G. (2017). Higher dietary cost is associated with higher diet quality: A cross-sectional study among selected Malaysian adults. Nutrients, 9(9), 1028. https://doi.org/ 10.3390/nu9091028

Popkin, B. M. (1993). Nutritional patterns and transitions. Population and Development Review, 19(1), 138-157. https://doi.org/ $10.2307 / 2938388$

Popkin, B. M. (2017). Relationship between shifts in food system dynamics and acceleration of the global nutrition transition. Nutrition Reviews, 75(2), 73-82. https://doi.org/10.1093/nutrit/nuw064

Popkin, B. M., Corvalan, C., \& Grummer-Strawn, L. (2020). Dynamics of the double burden of malnutrition and the changing nutrition reality. The Lancet, 395(10217), 65-74. https://doi.org/10.1016/ S0140-6736(19)32497-3

Popkin, B. M., \& Reardon, T. (2018). Obesity and the food system transformation in Latin America. Obesity Reviews, 19(8), 1028-1064. https://doi.org/10.1111/obr.12694

Pulker, C. E., Scott, J. A., \& Pollard, C. M. (2018). Ultra-processed family foods in Australia: Nutrition claims, health claims and marketing techniques. Public Health Nutrition, 21(1), 38-48. https://doi. org/10.1017/S1368980017001148

Raj, S. (2020). Influences of the nutrition transition on chronic disease. In D. Noland, J. A. Drisko, \& L. Wahner (Eds.), Integrative and functional medical nutrition therapy (pp. 17-29). Humana Press.

Raschke, V., \& Cheema, B. (2008). Colonisation, the New World Order, and the eradication of traditional food habits in East Africa: Historical perspective on the nutrition transition. Public Health Nutrition, 11(7), 662-674. https://doi.org/10.1017/S1368980007001140

Reardon, T., Tschirley, D., Dolislager, M., Snyder, J., Hu, C., \& White, S. (2014). Urbanization, diet change, and transformation of food supply chains in Asia. Michigan. Retrieved from http://www.fao. org/fileadmin/templates/ags/docs/MUFN/DOCUMENTS/MUS_ Reardon_2014.pdf

Reardon, T., Tschirley, D., Liverpool-tasie, L. S. O., Awokuse, T., Fanzo, J., Minten, B., et al. (2021). The processed food revolution in African food systems and the double burden of malnutrition. Global Food Security, 28, 100466. https://doi.org/10.1016/j.gfs.2020.100466

Redondo, M., Hernández-Aguado, I., \& Lumbreras, B. (2018). The impact of the tax on sweetened beverages: A systematic review. The American Journal of Clinical Nutrition, 108(3), 548-563. https://doi.org/10.1093/ajcn/nqy135

Reyes, M., Garmendia, M. L., Olivares, S., Aqueveque, C., Zacarías, I., \& Corvalán, C. (2019). Development of the Chilean front-ofpackage food warning label. BMC Public Health, 19, 906. https:// doi.org/10.1186/s12889-019-7118-1

Reyes, M., Taillie, L. S., Popkin, B., Kanter, R., Vandevijvere, S., \& Corvalán, C. (2020). Changes in the amount of nutrient of packaged foods and beverages after the initial implementation of the Chilean Law of Food Labelling and Advertising: A nonexperimental prospective study. PLoS Medicine. https://doi.org/10.1371/journal. pmed. 1003220
Rico-Campà, A., Martínez-González, M. A., Alvarez-Alvarez, I., Mendonça, R. D. D., de la Fuente-Arrillaga, C., Gómez-Donoso, C., $\&$ Bes-Rastrollo, M. (2019). Association between consumption of ultra-processed foods and all cause mortality: SUN prospective cohort study. BMJ, 365, 1949. https://doi.org/10.1136/bmj.11949

Ridberg, R. A., Bell, J. F., Merritt, K. E., Harris, D. M., Young, H. M., $\&$ Tancredi, D. J. (2019). A pediatric fruit and vegetable prescription program increases food security in low-income households. Journal of Nutrition Education and Behavior, 51(2), 224-230. https://doi.org/10.1016/j.jneb.2018.08.003

Ritchie, H., Reay, D. S., \& Higgins, P. (2018). The impact of global dietary guidelines on climate change. Global Environmental Change, 49, 46-55. https://doi.org/10.1016/j.gloenvcha.2018.02.005

Robinson, E., Fleming, A., \& Higgs, S. (2014a). Prompting healthier eating: Testing the use of health and social norm based messages. Health Psychology, 33(9), 1057-1064. https://doi.org/10.1037/a0034213

Robinson, E., Thomas, J., Aveyard, P., \& Higgs, S. (2014b). What everyone else is eating: A systematic review and meta-analysis of the effect of informational eating norms on eating behavior. Journal of the Academy of Nutrition and Dietetics, 114(3), 414-429. https:// doi.org/10.1016/j.jand.2013.11.009

Rockström, J., Edenhofer, O., Gaertner, J., \& DeClerck, F. (2020). Planet-proofing the global food system. Nature Food, 1(1), 3-5. https://doi.org/10.1038/s43016-019-0010-4

Ruel, M. T., Quisumbing, A. R., \& Balagamwala, M. (2018). Nutritionsensitive agriculture: What have we learned so far? Global Food Security, 17, 128-153. https://doi.org/10.1016/j.gfs.2018.01.002

Sánchez-Romero, L. M., Penko, J., Coxson, P. G., Fernández, A., Mason, A., Moran, A. E., et al. (2016). Projected impact of Mexico's sugar-sweetened beverage tax policy on diabetes and cardiovascular disease: A modeling study. PLOS Medicine, 13(11), e1002158. https://doi.org/10.1371/journal.pmed.1002158

Sartas, M., Schut, M., Proietti, C., Thiele, G., \& Leeuwis, C. (2020). Scaling readiness: Science and practice of an approach to enhance impact of research for development. Agricultural Systems, 183, 102874. https://doi.org/10.1016/j.agsy.2020.102874

Schoeppe, S., Alley, S., van Lippevelde, W., Bray, N. A., Williams, S. L., Duncan, M. J., \& Vandelanotte, C. (2016). Efficacy of interventions that use apps to improve diet, physical activity and sedentary behaviour: A systematic review. International Journal of Behavioral Nutrition and Physical Activity, 13(1), 127. https://doi.org/ 10.1186/s12966-016-0454-y

Shangguan, S., Afshin, A., Shulkin, M., Ma, W., Marsden, D., Smith, J., et al. (2019). A meta-analysis of food labeling effects on consumer diet behaviors and industry practices. American Journal of Preventive Medicine, 56(2), 300-314. https://doi.org/10.1016/j. amepre.2018.09.024

Sibhatu, K. T., \& Qaim, M. (2018). Review: The association between production diversity, diets, and nutrition in smallholder farm households. Food Policy, 77, 1-18. https://doi.org/10.1016/j.foodp ol.2018.04.013

Springmann, M., Godfray, H. C. J., Rayner, M., \& Scarborough, P. (2016). Analysis and valuation of the health and climate change cobenefits of dietary change. Proceedings of the National Academy of Sciences of the United States of America, 113(15), 4146-4151. https://doi.org/10.1073/pnas.1523119113

Springmann, M., Spajic, L., Clark, M. A., Poore, J., Herforth, A., Webb, P., et al. (2020). The healthiness and sustainability of national and global food based dietary guidelines: Modelling study. BMJ, 370, m2322. https://doi.org/10.1136/bmj.m2322

Srour, B., Fezeu, L. K., Kesse-Guyot, E., Allès, B., Méjean, C., Andrianasolo, R. M., et al. (2019). Ultra-processed food intake and risk of cardiovascular disease: Prospective cohort study (NutriNetSanté). BMJ, 365, 11451. https://doi.org/10.1136/bmj.11451 
Subrahmanyan, S., \& Gomez-Arias, J. T. (2008). Integrated approach to understanding consumer behavior at bottom of pyramid. Journal of Consumer Marketing, 25(7), 402-412. https://doi.org/10.1108/ 07363760810915617

Sushil, Z., Vandevijvere, S., Exeter, D. J., \& Swinburn, B. (2017). Food swamps by area socioeconomic deprivation in New Zealand: A national study. International Journal of Public Health, 62(8), 869-877. https://doi.org/10.1007/s00038-017-0983-4

Swinburn, B., Sacks, G., Vandevijvere, S., Kumanyika, S., Lobstein, T., Neal, B., et al. (2013). INFORMAS (International Network for Food and Obesity/non-communicable diseases Research, Monitoring and Action Support): Overview and key principles. Obesity Reviews, 14(S1), 1-12. https://doi.org/10.1111/obr.12087

Taillie, L. S., Busey, E., Stoltze, F. M., \& Dillman Carpentier, F. R. (2019). Governmental policies to reduce unhealthy food marketing to children. Nutrition Reviews, 77(11), 787-816. https://doi.org/ 10.1093/nutrit/nuz021

Taillie, L. S., Reyes, M., Colchero, M. A., Popkin, B., \& Corvalán, C. (2020). An evaluation of Chile's Law of Food Labeling and Advertising on sugar-sweetened beverage purchases from 2015 to 2017: A before-and-after study. PLOS Medicine, 17(2), e1003015. https://doi.org/10.1371/journal.pmed.1003015

Thaler, R. H., \& Sunstein, C. R. (2008). Nudge: Improving decisions about health, wealth, and happiness. Yale University Press.

Thorndike, A. N., Sonnenberg, L., Riis, J., Barraclough, S., \& Levy, D. E. (2012). A 2-phase labeling and choice architecture intervention to improve healthy food and beverage choices. American Journal of Public Health, 102(3), 527-533. https://doi.org/10. 2105/AJPH.2011.300391

Turner, C., Aggarwal, A., Walls, H., Herforth, A., Drewnowski, A., Coates, J., et al. (2018). Concepts and critical perspectives for food environment research: A global framework with implications for action in low- and middle-income countries. Global Food Security, 18, 93-101. https://doi.org/10.1016/j.gfs.2018.08.003

Turner, C., Kalamatianou, S., Drewnowski, A., Kulkarni, B., Kinra, S., \& Kadiyala, S. (2020). Food environment research in low- and middle-income countries: A systematic scoping review. Advances in Nutrition, 11(2), 387-397. https://doi.org/10.1093/advances/ nmz031

USDA Economic Research Service. (2019). Food prices and spending. USDA Economic Research Service.

van de Kamp, M. E., van Dooren, C., Hollander, A., Geurts, M., Brink, E. J., van Rossum, C., et al. (2018). Healthy diets with reduced environmental impact?-The greenhouse gas emissions of various diets adhering to the Dutch food based dietary guidelines. Food Research International, 104, 14-24. https://doi.org/10.1016/j.foodres. 2017.06.006

van Dooren, C., Marinussen, M., Blonk, H., Aiking, H., \& Vellinga, P. (2014). Exploring dietary guidelines based on ecological and nutritional values: A comparison of six dietary patterns. Food Policy, 44, 36-46. https://doi.org/10.1016/j.foodpol.2013.11.002

Vandevijvere, S., De Ridder, K., Fiolet, T., Bel, S., \& Tafforeau, J. (2019a). Consumption of ultra-processed food products and diet quality among children, adolescents and adults in Belgium. European Journal of Nutrition, 58, 3267-3278. https://doi.org/10.1007/ s00394-018-1870-3

Vandevijvere, S., Jaacks, L. M., Monteiro, C. A., Moubarac, J., GirlingButcher, M., Lee, A. C., et al. (2019b). Global trends in ultraprocessed food and drink product sales and their association with adult body mass index trajectories. Obesity Reviews, 20(S2), 10-19. https://doi.org/10.1111/obr.12860
Vargas-Meza, J., Jáuregui, A., Pacheco-Miranda, S., Contreras-Manzano, A., \& Barquera, S. (2019). Front-of-pack nutritional labels: Understanding by low- and middle-income Mexican consumers. PLOS ONE, 14(11), e0225268. https://doi.org/10.1371/journal.pone.0225268

Verly, E., Darmon, N., Sichieri, R., \& Sarti, F. M. (2020). Reaching culturally acceptable and adequate diets at the lowest cost increment according to income level in Brazilian households. PLoS ONE, 15(3), e0229439. https://doi.org/10.1371/journal.pone.0229439

Vermeulen, S. J., Park, T., Khoury, C. K., \& Béné, C. (2020). Changing diets and the transformation of the global food system. Annals of the New York Academy of Sciences. https://doi.org/10.1111/nyas.14446

Walton, K., Horton, N. J., Rifas-Shiman, S. L., Field, A. E., Austin, S. B., Haycraft, E., et al. (2018). Exploring the role of family functioning in the association between frequency of family dinners and dietary intake among adolescents and young adults. JAMA Network Open, 1(7), e185217. https://doi.org/10.1001/jamanetworkopen.2018.5217

Webb Girard, A., Waugh, E., Sawyer, S., Golding, L., \& Ramakrishnan, U. (2020). A scoping review of social-behaviour change techniques applied in complementary feeding interventions. Maternal \& Child Nutrition, 16(1), e12882. https://doi.org/10.1111/mcn.12882

Weinstein, M. (2005). The surprising power of family meals. How eating together makes us smarter, stronger, healthier and happier. Steerforth Press.

WFP. (2017). Counting the beans-The true cost of a plate of food around the world. WFP.

White, S., Schmidt, W., Sahanggamu, D., Fatmaningrum, D., van Liere, M., \& Curtis, V. (2016). Can gossip change nutrition behaviour? Results of a mass media and community-based intervention trial in East Java, Indonesia. Tropical Medicine \& International Health, 21(3), 348-364. https://doi.org/10.1111/tmi.12660

WHO. (2018). Healthy diet-Fact sheet No. 394. WHO.

WHO. (2020). Nutrition action in schools: A review of evidence related to the Nutrition-Friendly Schools Initiative. WHO.

Wijesinha-bettoni, R., Khosravi, A., Ramos, A. I., Sherman, J., Hernandezgarbanzo, Y., Molina, V., et al. (2021). A snapshot of food-based dietary guidelines implementation in selected countries. Global Food Security, 29, 100533. https://doi.org/10.1016/j.gfs.2021.100533

Willett, W., Rockström, J., Loken, B., Springmann, M., Lang, T., Vermeulen, S., et al. (2019). Food in the Anthropocene: The EATLancet Commission on healthy diets from sustainable food systems. The Lancet, 393(10170), 447-492. https://doi.org/10.1016/ S0140-6736(18)31788-4

Workicho, A., Belachew, T., Ghosh, S., Kershaw, M., Lachat, C., \& Kolsteren, P. (2019). Burden and determinants of undernutrition among young pregnant women in Ethiopia. Maternal \& Child Nutrition, 15(3), e12751. https://doi.org/10.1111/mcn.12751

Yiga, P., Seghers, J., Ogwok, P., \& Matthys, C. (2020). Determinants of dietary and physical activity behaviours among women of reproductive age in urban sub-Saharan Africa: A systematic review. British Journal of Nutrition, 124(8), 761-772. https://doi.org/10. 1017/S0007114520001828

Young, C., Campolonghi, S., Ponsonby, S., Dawson, S. L., O’Neil, A., Kay-Lambkin, F., et al. (2019). Supporting engagement, adherence, and behavior change in online dietary interventions. Journal of Nutrition Education and Behavior, 51(6), 719-739. https://doi. org/10.1016/j.jneb.2019.03.006

Zaltman, G. (2003). How customers think: Essential insights into the mind of the market. Harvard Business School Press. 


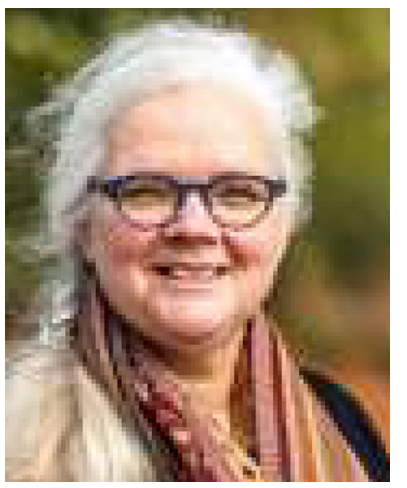

I. D. Brouwer $\mathrm{PhD}$ is Associate Professor Food Systems for Healthier Diets at the chairgroup Global Nutrition, Division of Human Nutrition and Health, Wageningen University, the Netherlands. She leads of the Flagship Food Systems for Healthier Diets under the CGAIR - A4NH research programme led by IFPRI, in collaboration with Bioversity International, CIAT, IFPRI, IITA in Bangladesh, Vietnam, Ethiopia and Nigeria to guide transformations of food systems toward healthier diets for poor populations in a sustainable and equitable way. She also leads the BMGF/FCDO funded project on Increasing Fruit and Vegetable Intakes in Vietnam and Nigeria, using consumer and retailer oriented interventions. She also contributes to the FAO guidance to development of foodbased dietary guidelines, globally and in Ethiopia.

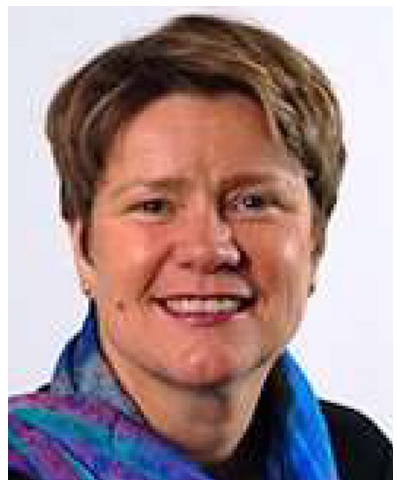

M. L. van Liere $\mathrm{PhD}$ is a public health nutrition expert with 30 years of experience in international development, focusing on food and nutrition security, maternal and child nutrition, programme and project management, and multisectoral and multi-stakeholder partnerships between public and private sectors. She has worked for international nutrition organizations, research and public health institutes, and private sector and has lived and worked in Bangladesh, Bénin, France, Switzerland and the Netherlands.

Marti has engaged private sector companies in nutrition (GAIN, Unilever), initiated new work areas (adolescent nutrition, work force nutrition) and set up, managed and supported global collaboration platforms (SUN Business Network, National Information Platforms for Nutrition, Healthy Mothers Healthy Babies Consortium). She has a MSc and PhD in Human Nutrition from the University of Wageningen, the Netherlands.

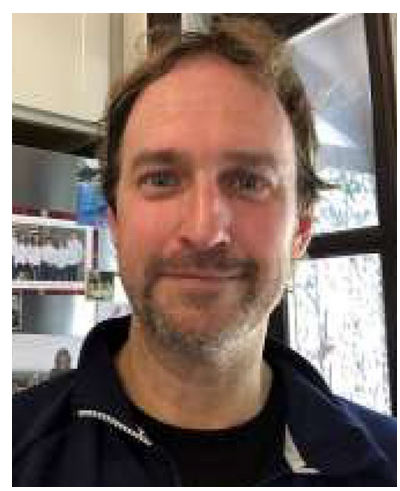

A. de Brauw $\mathrm{PhD}$ is a Senior Research Fellow in the Markets, Trade and Institutions Division of the International Food Policy Research Institute (IFPRI). He has a PhD in Agricultural and Resource Economics from the University of California at Davis, and prior to joining IFPRI he was an Assistant Professor of Economics at Williams College. His research agenda has focused on understanding impacts of interventions on rural populations, including those working to improve nutritional status among beneficiaries; the effects of migration on source households; and changing food systems. Much of his research is derived from primary survey work, usually designed for evaluative purposes; he has helped design, plan, and conduct multi-topic household surveys, in Africa, Asia, and Latin America. His research is published widely in development economics, agricultural economics, and nutrition journals including the Journal of Human Resources, Journal of Development Economics, World Bank Economic Review, the American Journal of Agricultural Economics, the British Journal of Nutrition, and the Journal of Nutrition.

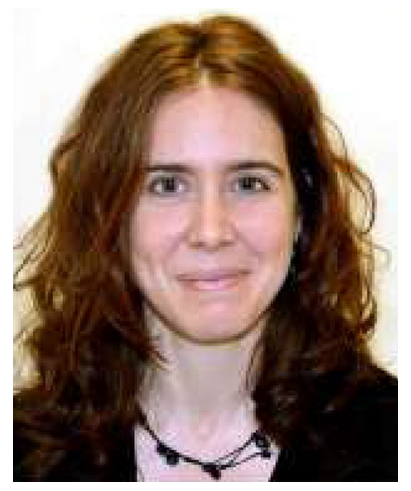

P. Dominguez-Salas graduated as a Veterinarian (Zaragoza University, 1998) and in Food Sciences and Technology (Zaragoza University, 2001) and worked in food safety for 5 years. After that, she obtained an MSc (2007) and $\mathrm{PhD}$ (2013) in International Public Health Nutrition at the London School of Hygiene and Tropical Medicine, UK, where she also worked as assistant professor in Nutrition-sensitive agriculture. She is now associate professor the Natural Resources Institute (NRI), University of Greenwich, UK. Her research deals with the role of animal-source foods and livestock in enhancing nutrition security in low-income countries, particularly in Africa, with interest in aspects such as food systems, food safety or gender. She is in a joint position with the International Livestock Research Institute, Kenya.

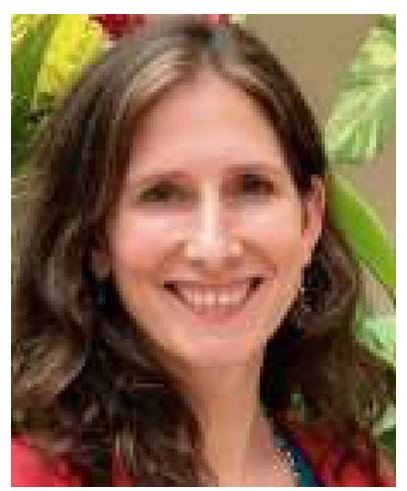

A. Herforth $\mathrm{PhD}$ conducts research on food metrics. Her current research focus is on measuring diet quality globally, affordability of nutritious diets, and food environments. This work stems from over a decade of consulting for international organizations on the topic of linking agriculture, food systems and nutrition, including with the World Bank, FAO, WHO, UNICEF, CGIAR, GAIN, USAID and GIZ. She has worked in Africa, South Asia, and Latin America, including with agricultural and indigenous communities. She holds a $\mathrm{PhD}$ in International Nutrition from Cornell University, M.S. in Food Policy from Tufts University, and a B.S. in Plant Science from Cornell University. Dr. Herforth co-founded and co-leads the Agriculture-Nutrition Community of Practice (Ag2Nut), a professional community of over 7,500 members from 130 countries. She is a Senior Research Associate in the Department of Global Health and Population at the Harvard T.H. Chan School of Public Health, and a Visiting Senior Researcher in the Division of Human Nutrition and Health at Wageningen University \& Research.

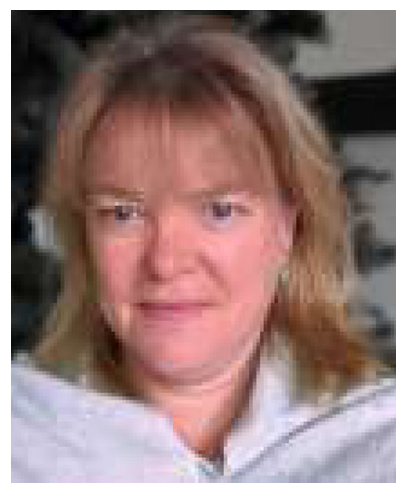

G. Kennedy Director of Food Systems, USAID Advancing Nutrition. Dr. Kennedy joined USAID Advancing Nutrition in 2020 and is responsible for a portfolio of USAID investments on food systems to improve diet quality, focusing on availability and affordability of safe, nutritious foods in markets, consumer demand for safe, nutritious foods and the enabling environment for a safe and healthy diet. Prior to joining USAID Advancing 
Nutrition, Dr. Kennedy was Senior Scientist with Bioversity International (now the Alliance of Bioversity and CIAT) and worked with the CGIAR Research Program, Agriculture for Nutrition and Health. Her areas of interest include diet quality, diet diversity, agrobiodiversity and food systems.

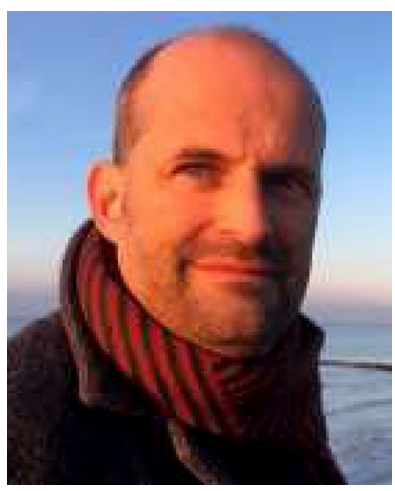

C. Lachat is Associate Professor at the Department of Food Technology, Safety and Health at Ghent University Belgium. He lectures courses in food and nutrition policies, nutritional epidemiology, planning and project design and nutrition-sensitive interventions.

His main interest is to develop effective approaches to enhance the nutritional status of vulnerable populations in lowand middle-income countries. These approaches are evaluated using both intervention and observational study designs, guided by rigorous assessment of evidence and systematic reviews. In addition to empirical research, he actively develops new knowledge with regard to collection, management and integration of food intake data and ways to increase quality of nutrition research and capacity for better policies and practices.

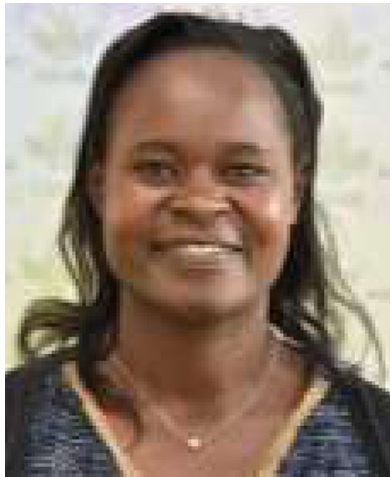

E. B. Omosa is a senior nutrition specialist at the International Livestock Research Institute (ILRI) currently working with a USAID funded Feed the Future Program Accelerated Value Chain Development (AVCD) where she coordinates nutrition activities across ILRI, and other 2 Cconsultative Groups for International Agricultural Research centres with the aim of improving economic growth, resilience and food security and nutrition of smallholder farmers, especially women and children in Kenya. Esther has worked in both humanitarian and development settings in Africa supporting deprived population through livelihoods, food security and social protection interventions. She is passionate about collaboratively working with vulnerable populations to utilize local resources in transforming food systems while strengthening the understanding of the links between Agriculture (and livestock) and human nutrition and well being. She holds a BSc in Foods, Nutrition and Dietetics and a Master in Public Health and Epidemiology.

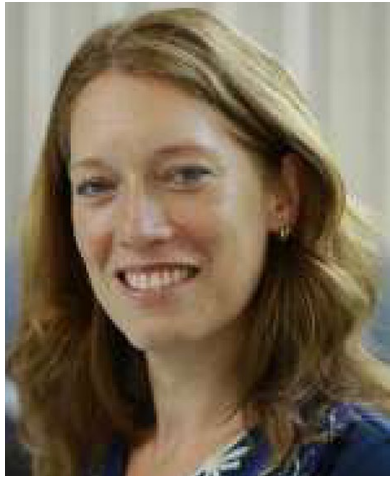

E. F. Talsma $\mathrm{PhD}$ is an Assistant Professor at the Division of Human Nutrition and Health within the group of Global Nutrition. Her research focuses on healthy diets in low and middle income countries, with a special focus on women, children and adolescents. Improvements in the food environment as well as developing indices to measure healthy diets are of special interest to her. And how can we make our diets more healthy but also sustainable by applying a food system approach is a key question throughout her work. She has ample experience with conducting research in these areas while living in Africa, Asia and Latin America. At the moment she supervises $9 \mathrm{PhD}$ students in various middle income countries on the above mentioned topics. Currently she is co-cluster lead of Diagnosis and Foresight cluster of the Flagship Food Systems for Healthier Diets under the CGAIR funded Agriculture for Nutrition and Health research programme.

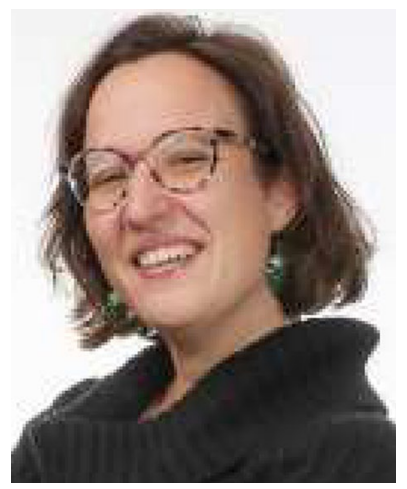

S.Vandevijvere is a senior public health nutrition scientist and her research focuses on nutrition policies for obesity prevention globally. Her work aims to support the development and implementation of policies to effectively and equitably improve the quality of population diets. In particular she has an interest in the role of food environments in determining people's dietary habits and how to hold governments and food businesses to account for their actions to create healthy food environments to effectively reduce obe-

sity. She is a member of the leadership team of the International Network for Food and Obesity / non-communicable diseases Research, Monitoring and Action Support (INFORMAS), which aims to monitor, benchmark and support public and private sector actions to create healthy food environments and reduce obesity and non-communicable diseases. She has more than 150 publications in peer reviewed journals.

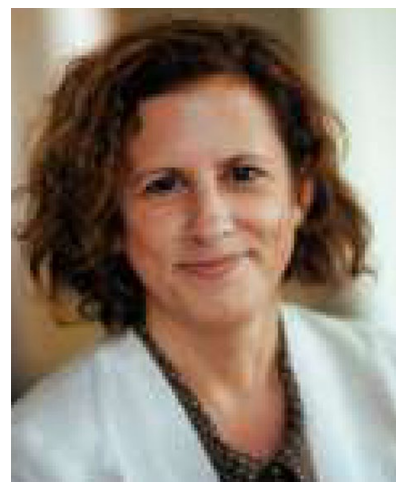

J. Fanzo $\mathrm{PhD}$ is the Bloomberg Distinguished Professor of Global Food Policy and Ethics at the Berman Institute of Bioethics, the Bloomberg School of Public Health, and the Nitze School of Advanced International Studies at the Johns Hopkins University. She also serves as the Director of Hopkins' Global Food Policy and Ethics Program, and as Director of Food \& Nutrition Security at the JHU Alliance for a Healthier World. From 2017 to 2019, Jessica served as the Co-Chair of the Global Nutrition Report and the UN High Level Panel of Experts on Food Systems and Nutrition.

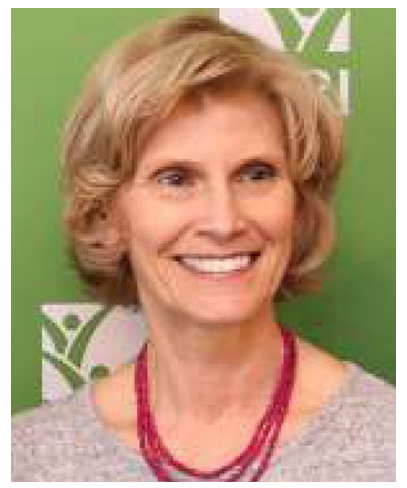

M. Ruel is a nutritionist, Director of the Poverty, Health, and Nutrition Division at the International Food Policy Research Institute (IFPRI). Dr. Ruel has worked for more than 35 years on policies and programs to alleviate poverty, food insecurity and malnutrition in low- and middle-income countries. She has published extensively on topics related to maternal and child nutrition, infant and young child feeding practices and related indicators, urban food security and nutrition, and on the 
linkages between agriculture, food systems, nutrition, and health. At IFPRI, she built a team and led a large research portfolio on the evaluation and strengthening of a range of multi-sectoral, nutrition-sensitive programs and policies; and promoted uptake of the evidence generated for policymaking. Dr. Ruel has served on various international expert committees, including the WHO - STAGE (Strategic and Technical Advisory Group of Experts) on Maternal, Newborn, Child, Adolescent Health and Nutrition. Dr. Ruel received the American Society for Nutrition Kellogg Prize for lifetime achievement in nutrition in 2019.

\section{Authors and Affiliations}

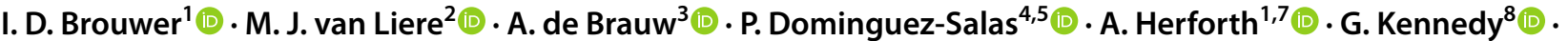

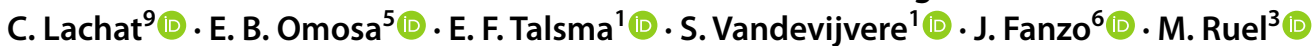

M. J. van Liere

marti.j.vanliere@gmail.com

A. de Brauw

a.debrauw@cgiar.org

P. Dominguez-Salas

P.DominguezSalas@greenwich.ac.uk

A. Herforth

anna@annaherforth.net

G. Kennedy

gina_kennedy@jsi.com

C. Lachat

Carl.Lachat@ugent.be

E. B. Omosa

E.Omosa@cgiar.org

E. F. Talsma

elise.talsma@wur.nl

S. Vandevijvere

stefanie.vandevijvere@wur.nl

J. Fanzo

jfanzo1@jhu.edu
M. Ruel

m.ruel@cgiar.org

1 Division of Human Nutrition and Health, Wageningen University, P.O. Box 17, 6700 AA Wageningen,

The Netherlands

2 Independent Consultant Affiliated with Wageningen University, Wageningen, The Netherlands

3 International Food Policy Research Institute, Washington, D.C., USA

4 Natural Resources Institute, University of Greenwich, London, UK

5 International Livestock Research Institute, Nairobi, Kenya

6 Bloomberg School of Public Health, Johns Hopkins University, Baltimore, USA

7 Harvard T.H. Chan School of Public Health, Boston, USA

8 Global Alliance for Improved Nutrition, Washington, D.C., USA

9 Department of Food Technology, Safety and Health, Ghent University, Ghent, Belgium 